\title{
An Apodictic Review on Recent Approaches in Enzyme Technology
}

\author{
Chithra Ashok 1(D), Dinesh Palanimuthu ${ }^{1 \mathbb{D}}$, Sharmila Devi Velusamy Selvadurai ${ }^{1 \mathbb{D}}$, Rudha Varshini \\ Ammasai ${ }^{1}$ (D), Preethi Pethappampatti Senthilkumar 1 ${ }^{\text {(D) }}$, Rajaseetharama Sekar 1,* (D) \\ 1 Department of Biotechnology, Bannari Amman Institute of Technology, Sathyamangalam, Erode, Tamil Nadu, India- \\ 638401 \\ * Correspondence: rajaseetharama@bitsathy.ac.in (R.S.);
}

Scopus Author ID 57222124942

Received: 21.06.2021; Revised: 25.07.2021; Accepted: 29.07.2021; Published: 8.08.2021

\begin{abstract}
Enzymes are the most powerful biochemical moieties, predominantly the working tools in all living systems. Many studies have revealed the usage of various enzymes even in the pre-historical periods. Enzymes are known to be the extremely active biocatalyst that is widely involved in many metabolisms. Living systems explore these biomolecules for their metabolism and are exhaustively explored for various industrial and clinical applications. Due to the increasing need for enzyme-based products, various recent research focuses on exploring distinct enzymes \& enzyme sources with relatively enhanced characteristics. The elegant motive of this review is to enable the readers and enzyme researchers to compend the basics of enzymes, explore the enormous recent clinical \& industrial applications of enzymes like amylase, cellulase, protease, lipase, and esterase. And also, the review highly emphasizes the various enzyme source and their enriched properties like enzyme activity, annotated by recent research works carried out by various research teams across the globe. The review also accentuates the recent advancements in production technologies and high throughput activity prediction assays for the above-mentioned industrially important enzymes.
\end{abstract}

Keywords: enzymes; enzyme sources; therapeutical enzymes; industrial enzymes; high throughput enzyme assays.

(C) 2021 by the authors. This article is an open-access article distributed under the terms and conditions of the Creative Commons Attribution (CC BY) license (https://creativecommons.org/licenses/by/4.0/).

\section{Introduction}

Enzymes are the most basic biocatalyst for the catalysis reaction of the substrate. It is a globular protein of high molecular weight with a long linear chain of amino acids like other proteins and having specific properties that depend on the structure. They are made up of a three-dimensional complex of polypeptide chains [1]. Enzymes are available in a wide source such as plants, animal tissues, and several microorganisms, and they are used in the textile and manufacturing industries as an alternative to toxic chemicals for many processing procedures [2]. Nowadays, they are rapidly important in some sectors like pharma, green chemistry, and sustainable technology. The global enzyme market in 2020 was around USD 7.5 billion, and the annual growth rate between 2016 to 2021 is $8.2 \%$ [3,4]. The global enzyme market is planned to show high profitable growth of enzymes in the field of detergent, pharmaceutical, and even in the chemical sectors. Enzymes are more sensitive to various entities; they get inactive in high temperatures, acids, radiation and are also easily denatured by some biological factors [5]. Enzymes are powerful biocatalysts. Lowering the activation energy can increase 
the reaction rate in lower concentration and carry out the reaction without consuming and undergoing any changes [6]. They are specific in their function and reaction, with that different enzyme performs various mechanism including covalent-catalysis, acid-base, electrostatic $[7,8]$. The biochemical reaction carried out by plants, microbes, and animals is the result directly produced by the enzyme catalysis. Mostly, the biochemistry background is indirectly or directly related to enzyme history. The basic building blocks of the living system have the capability to use biocatalyst known as enzyme effectively [9]. Enzymes have vast applications in the pharmaceutical industry to treat various ailments like cancer, etc. They are used to reduce tumor tissue inflammation, infectious pathogens prevention from tumor tissues, and so forth [10]. Not only in the pharma sector, but they also have more applications in other fields like food processing, textile processing, paper industry, etc. The enzymes reviewed in this study are amylase, cellulase, protease, lipase, and esterase. These enzymes have more therapeutic potential [11-13]. Amylase has been considered important among the other enzymes, and the amylase produced from pineapple stem is about $34.4 \%$ and from the lotus stem is about 20$30 \%$ [14]. Amylase is produced by animals, fungi, molds, bacteria, and plants but bacteria and fungi are the most important sources for amylase production in the industries [15]. It is used to degrade the starch into oligosaccharides; also, it will improve the yield of the product. The raw starch hydrolysis by amylase was a major breakthrough in the starch processing industry, reducing the cost of starch-based products [16]. It can be used in fruit drinks, textile, detergent, and alcohol \& beverages industries [17]. It is also used as functional biomaterials such as adsorbent, cosmetic, carrier, agriculture, or structure-directing agent in food, pharmaceutical, paper, and tissue engineering [18]. Cellulase is an essential industrial enzyme in the global enzyme market [19]. In oil \& petroleum, food processing fields, the cellulase enzyme plays a major role. The most abundant biomass (lignocellulose) acts as a renewable source for biofuels $\&$ other value-added products. And efficiently hydrolyzed by the microbial cellulases. So, it was the most important research field for researchers and industrialists [20,21]. The protease enzymes are also known as proteolytic, peptidase, or proteinase, which are present in bacteria, plants, animals, some kind of algae, and also viruses. Approximately $40 \%$ of total worldwide sales in the industrial enzyme are protease. Protease enzymes are available from many organisms, even though some are only considered for commercial uses [22]. Protease can degrade the proteins which are mainly used in the animal feed and leather industry [6]. Lipase plays an important role in dairy product fermentation since ancient days [23]. Lipid metabolism in the way of in-situ and the multifaceted ex-situ application in industries were carried out by lipase. Lipase can degrade oil and fatty acids. It is mostly used in the detergent and dairy industries. Due to their interesting properties, lipase plays a role in different modern areas, for example, agro-substance, paper assembling, cosmetics, etc. [24]. Esterase can degrade the ester into alcohol and acid, which is also considered an important enzyme in biotechnology. Due to its capability, esterase can survive in the environment, and it is distributed widely in animals, microorganisms, and plants. In organic solvents, they can be active and stable. It is one of the tremendous properties of the esterase [25,26]. It plays an important role in industries like oleochemical, dairy, and biodiesel. Also, thermostable esterase are suited for industries due to their stabilization in high temperature [27,28]. Hence, the various enzyme plays several commercially and clinically significant role in this industrial era. This review completely focuses on highlighting recent diverse application, source, bioprocess approaches, and high throughput assay techniques. 


\section{Materials and Methods}

This review gives the cumulative idea about the basis of the enzyme, sources of enzyme, application, high throughput techniques used for enzyme assays, and advanced bioprocess approaches. Various recent scientific researches and reviews have supplemented this article. This review is comprised of 175 references covering the above-mentioned topics. Among these references, the most cited papers are recent published articles (around the years of 2018-2021, about $61.71 \%$ ). This is to bring out the enzyme importance in recent years and its novel application around the multidisciplinary fields. The second most cited reference belongs between 2011-2017, around 26.29\%. After that, $10.29 \%$ of sources were cited between 2001 and 2010, and the remaining $1.71 \%$ is below 2000 . The details are graphically explained in Figure 1.

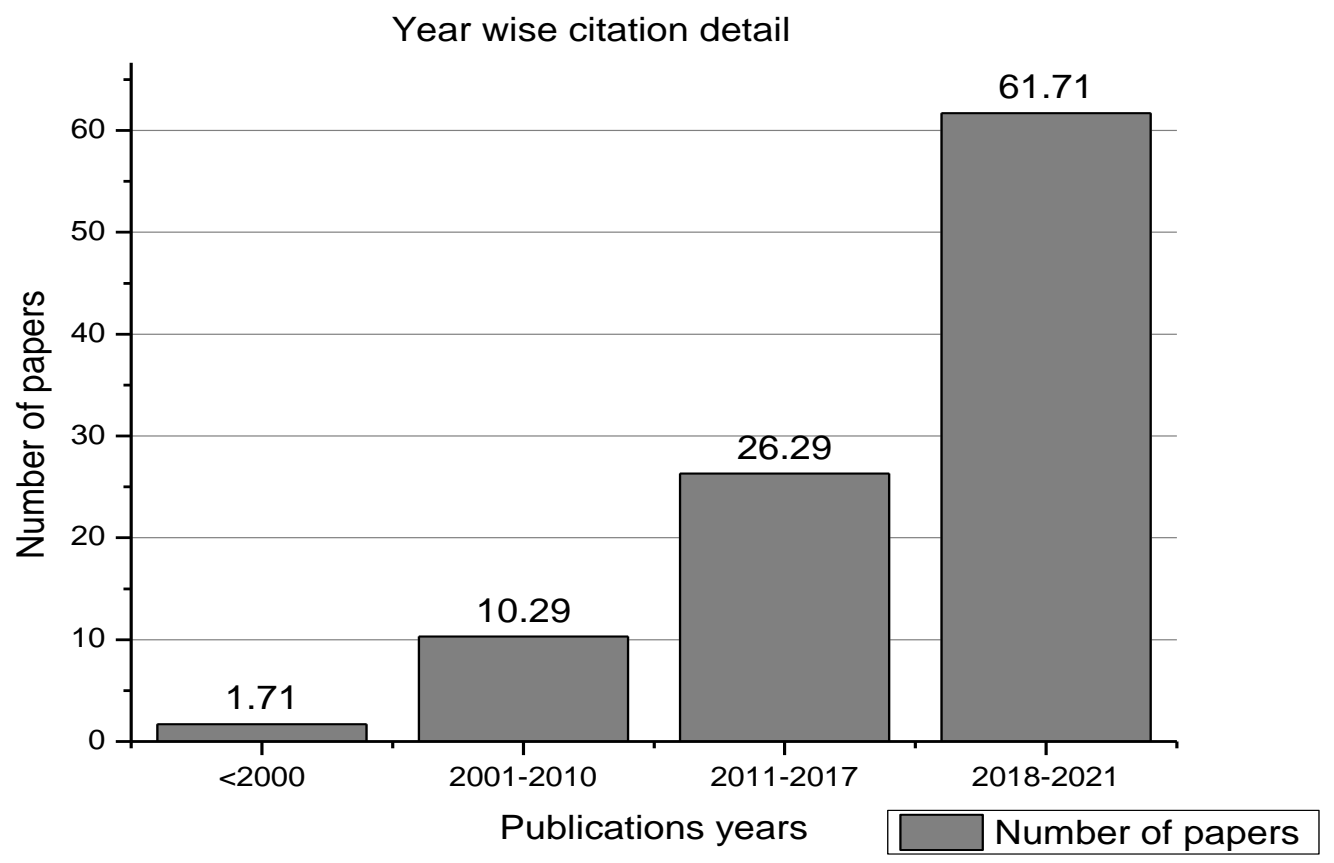

Figure 1. Year-wise citation detail.

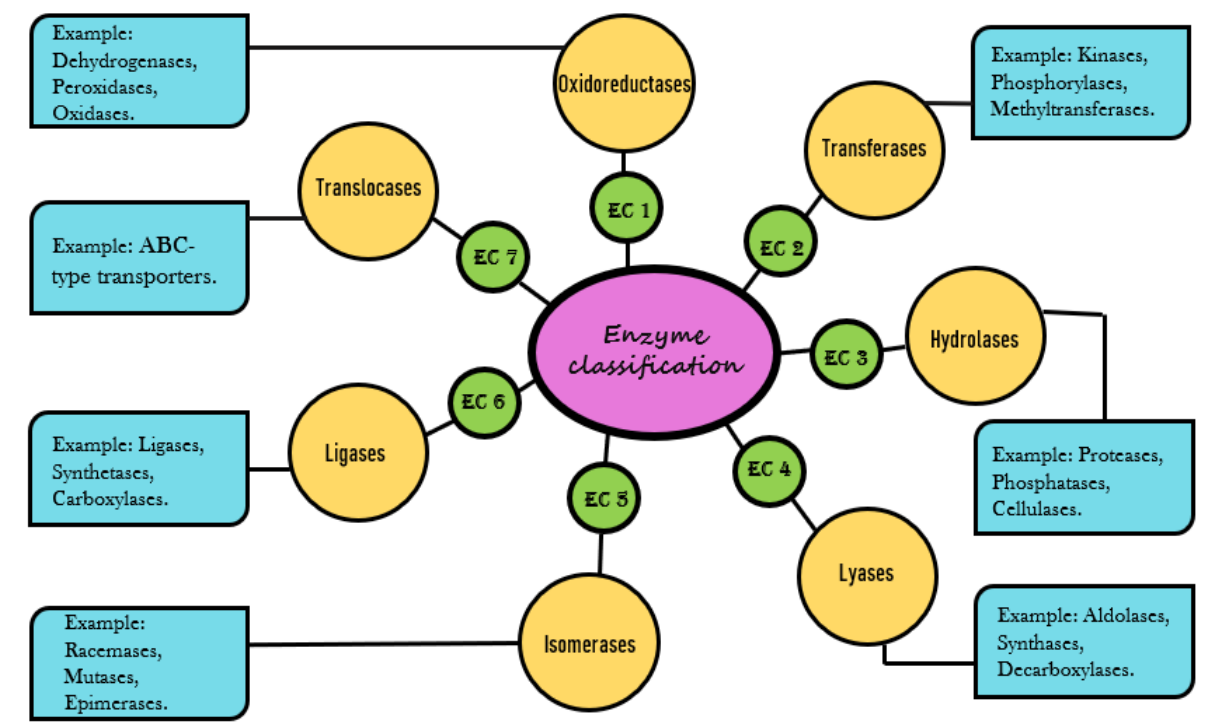

Figure 2. Enzyme Stratification. 


\section{Enzyme basics \& Stratification}

Enzymes have exhibited increased effectiveness and efficiency in many industrial processes and products, which has environmental benefits. This enzyme represents the protein groups and widely plays an important role in various processes like cell division, expression of genes, important immune system reactions, and metabolic activities. Enzymes are classified into seven classes, as shown in Figure 2 [29].

The enzyme oxidoreductase catalyzes the oxidation and reduction reaction by transferring the electron from one particle to another particle also removing the hydrogen atom utilizing the enzymes. These enzyme groups mainly utilize cofactors such as NADP+ and NAD+. This enzyme is found in algae, bacteria, fungi, plants, and animals. Thermoascus aurantiacus, Neurospora crassa, Lentinus similis like some fungi and bacteria such as Enterococcus faecalis, and Lactobacillus kefir are used to catalyze the lytic polysaccharide monooxygenases (LPMOs) substrates. It has applications in various sectors such as the immunological sector, medicine, and industries like fruit ripening and growth, cell wall metabolism, pathogens defense mechanism, etc., [30]. Examples are dehydrogenases, peroxidases, oxidases, reductases.

The enzyme class transferases catalyzed the transfer of a particular functional group (e.g., phosphate, acyl, and amino groups) from one substance to another. This enzyme is involved in the hundreds of various pathways in the biological reaction. It also involves the myriad cell reaction [29]. The Cytosolic Glutathione transferases (GSTs), which is a common transferase enzyme, are present in insects, plants, fungi, bacteria, and mammals. It is helpful in cancer monitoring and diagnostics, drug metabolism, drug, and pro-drug design, which is also used in the field biosensor for detecting the herbicide. The examples are trans aldolases, methyltransferases, kinase, transaminases.

Hydrolase enzymes catalyze the cleavage of the hydrolytic bond such as $\mathrm{C}-\mathrm{O}, \mathrm{C}-\mathrm{C}$, and $\mathrm{C}-\mathrm{N}$. This enzyme also transfers the water molecules; that is, the hydrolysis of the substrate can be catalyzed by the hydrolases enzymes. Few important examples of hydrolase enzymes are included below. This enzyme is mostly found in bacteria and filamentous fungi, like Aspergillus niger, Trichoderma reesei, and Bacillus, which are also present in some high-order organisms like gastropods, arthropods, plants, insects, and marine algae [29]. Hydrolase enzyme is used in all major industrial fields. Examples of hydrolase are protease, amylase, cellulase, and lipase.

Lyases enzymes catalyze the C-C, C-O, C-S, and C-N bond cleavage by eliminating the other bonds. Lyases can remove or add water, carbon dioxide, and ammonia elements from double bonds through the non-hydrolytic bond-breaking reaction. These enzymes are involved in the signal transduction pathways, anabolic and metabolic pathways, and DNA repair mechanisms [29]. It plays a key role in the food and chemical industries, preparation of natural products, and pharmaceutical intermediates. This enzyme presence was observed in plants, animals, and some microorganism's genera like Fusarium, Aspergillus, Penicillium [31]. Aldolases, decarboxylases, and synthases are examples of lyases enzymes.

The isomerase is the enzyme class that comes under the fifth group of enzyme commission (EC) classification (EC - 5). The isomerases catalyzed the isomerization reactions or intermolecular rearrangements. It is categorized into seven sub-classes: They were, racemases and epimerases, intramolecular oxidoreductases, intramolecular transferases, intramolecular lyases, cis-trans isomerases, isomerases altering macromolecular conformation. 
The enzyme helps in interconversions which occurs in most organisms. For example, alanine racemase catalyzes the racemization of amino acids. Isomerases are subdivided into, cis-trans isomerases, intramolecular oxidoreductases, racemases \& epimerases, intramolecular transferases, intramolecular lyases [32]. In most living organisms, the isomerase catalyzes the biochemical reaction, particularly carbohydrate metabolism, up to 4\% [33]. They have important uses in biotechnology, drug discovery, and organic synthesis. For example, a novel glucose isomerase enzyme extracted from Caldicoprobacter algeriensis, has excellent thermostable property and gained industrial importance in recent years. And also, protein disulfide isomerase (PDI) had been overexpressed and helps in the proliferation of cancer cells. The anti-cancerous activity has been elicited on the Epithelial ovarian cancer models by targeting the PDI [34,35]. Examples are glucose isomerase, sucrose isomerase \& D- arabinose isomerase.

The ligase is the class of enzyme that constitutes the sixth group of classification (EC 6). It was further divided into six sub-classes based on the formation of bonds. They are phosphoric-ester, Carbon-oxygen, Carbon-nitrogen, Carbon-Sulphur, Carbon-carbon, and Nitrogen metal. The ligase catalyzes the joining of two or more molecules together, which are connected to the hydrolysis of analogous or ATP molecules. As they catalyze the reaction that generates the new molecule, they are termed Synthetases [36]. It involves biologically essential reactions, and it was about 81 ligases that play an important role in central metabolism [37]. For Example, DNA ligase is commonly used to join DNA fragments [38]. DNA ligase is an example of ligase.

An enzyme translocase can catalyze the molecules or ions translocation across the cell or separation in membranes which frequently hydrolysis the ATP, called translocases (EC - 7). The translocase is the new class of enzyme that catalyzes the translocation of ions/molecules within membranes or across the cell with the hydrolysis of ATP. It is also subdivided into six subclasses. By the translocated ion/molecule, they are divided into six subclasses. The enzyme catalyzing the translocation of hydrons, catalyzing the translocation of amino acids and peptides, catalyzing the translocation of inorganic cations, catalyzing the translocation of carbohydrates and their derivatives, catalyzing the translocation of other compounds, catalyzing the inorganic anions and their chelates belongs to this class [39]. It plays an essential role in the mitochondrial transport system. Its deficiency may lead to a disorder (i.e.) Carnitineacylcarnitine translocase deficiency [40]. An example of a translocase enzyme is amino phospholipid translocase.

\section{Enzymes in Industries}

Amylase enzyme has very significant importance in the industrial sector. It is extensively used in detergent industries. The crude enzyme obtained from Bacillus mojavensis is used in laundry industries because of its alkaline conditions activity and stability at a wide temperature range $\&$ with other detergent components such as anionic \& non-ionic surfactants and other oxidizing agents [41]. The Amylase soap-nut extract combination can destain the blood-stained cloth in 30 minutes [42]. Amylase is used in the detergent industry because of its sustainability and high stain-removing efficiency. At low temperatures, amylase, which is cold-active like amy 175, is produced, and it has increased the power of stain removing efficiency [43]. Cold active amylases are used as an eco-friendly additive in detergents. Low temperature and higher $\mathrm{pH}$ are the suitable conditions for using amylase as a detergent additive 
[44]. In the food industry, amylase will increase the quality and texture of the bread. The addition of microbial amylase with a specific volume $(7.7 \%)$, reduces the hardness \& chewiness by $11.5 \%$ and $17.2 \%$, respectively. It also increased the texture profile by increasing the size and number of holes $[45,46]$. Amylase enzyme extracted from Rhizomucor miehei is used as a high potential candidate in food industries [45]. Multiple amylases from microbes and fungi were used in industries. Bacterial amylases are mostly used in many industrial processes due to their higher stability[47].

Amylase is used broadly in the production of bio-fuel. The second-wide application of amylase in the industry is bioethanol production. Initially, the slurry was gelatinized with a jet cooker. Then, it liquified using thermally stable $\alpha$-amylase, which results in the saccharification and the release of fermentable sugars. It is subsequently fermented, and bioethanol is produced [48]. Using corn amylase instead of yeast in the process of dry-grind reduces enzyme usage, and it is combined and used in bioethanol production [49]. Bioethanol is produced from the biorefinery waste stream by treating enzymes like amylase with wheat bran using saccharification and fermentation methods [50].

Cellulase has an application in the pulp processing industry. Due to their potentials in paper pulp modification, the paper-making industries relied on lignocellulosic enzymes such as cellulase and xylanase. In combination with other enzymes, cellulase was used in biobleaching, deinking of waste papers, and in the modification of paper \& pulp characteristics [51]. Cellulase is the third-highest enzyme used in industries for various applications. It is used in applications like bio pulping, bio stoning, bio bleaching, etc. In bio pulping, enzymes are made to break down, and by bio bleaching, the brightness of paper is increased [52]. Recycling cellulase with fresh cellulase helps to dissolve the pulp more effectively [53]. Lycopene \& soluble dietary fibers (SDF) extraction using cellulase can reduce coronary heart disease risk, obesity, stroke, diabetes, and other diseases. Lycopene has antioxidant \& anti-tumor properties. The enzymatic approach in the lycopene $\&$ SDF extraction from tomato will be considered safe when compared to chemical means. The use of cellulase and laccase will increase the yield of lycopene and SDF by $23.8 \%$ and $72.3 \%$, respectively [54]. Cellulase was a cell wall degrading enzyme which has an application in the extraction of lycopene from tomatoes [55]. Extraction of soluble dietary fiber from potato pulp is first pre-treated with cellulase and xylanase, which gives better yield and also enhances the physiological and functional properties of SDF [56].

The enzyme protease is broadly used in leather industries. Leather industries follow the conventional process that uses hazardous chemicals such as sodium sulfide and lime. It results in issues such as effluent disposal and pollution. The protease is used to hydrolyze the noncollagenous protein of the skin and remove globulins \& albumins [57]. Keratinolytic protease is an environmentally friendly biocatalyst that is used in the production of high-quality leather [58]. Proteases are used in place of traditional chemical agents, which reduces pollution [59]. Protease has important applications in the food and food processing industries. It is used in cheese ripening, flavor development, and milk coagulation in dairy industries and is also used in meat processing industries. In the cheese production process, proteases are added to milk in order to hydrolyze cheese. Proteases are also used in tenderizing meat [60]. In the baking industry, it is used in dough preparations and gluten development. In seafood processing, it is used in the production of fishmeal and enhances oil recovery [61]. Aspartic proteases are used in food and beverages [62]. 
Lipase plays an important role in degrading lipid pollutants. The presence of lipid pollutants in the water can cause severe problems like the formation of the lipid layer over the water, which affects the aquatic ecosystem. Similarly, the lipid pollutants present in the soil can cause difficulties in water movement, reduce the ability of water to bind to soil particles, and limit the aeration, which adversely affects the ecosystem. The lipase, which is immobilized with cellulosic particles, was used to degrade the lipids and grease accumulated in wastewater pipelines [63]. To degrade lipid accumulated oil bodies, TAG (triacylglycerol) lipases are responsible for the lipid productivity enhancement in microalgae [64].

Due to the esterase solid remediation property, it can degrade the herbicides such as metsulfuron-methyl, chlorimuron-ethyl, and tribenuron-methyl. The immobilized esterase can be used in the remediation of soil contaminated with pesticides [65]. The calorimetric method is used to determine the soil's esterase activities in which fatty acids esters are linked to pnitrophenol as substrates [66]. Novel esterase, which was derived from metagenomics, plays a major role in diesel-oil degradation [67]. Enzymes are catalytic biosensors that bind to the analyte \& converts into products. By the electrochemical transducer, read out the target consumption during the conversion. The enzyme will be selected based on the target, such as acetylcholine esterase for acetylcholine, cholesterol oxidase for cholesterol, glucose oxidase for glucose, horseradish peroxidase for $\mathrm{H}_{2} \mathrm{O}_{2}$, and tyrosinase for bisphenol. Most of the enzymes act as a biocatalyst as well as a bioreactor for many biological processes, such as $\mathrm{H}_{2} \mathrm{O}_{2}$ acts as a signaling molecule for cell death monitoring, immune cell activation, root growth, and stomatal closure. So, it is important to biosensing in many platforms [68].

\section{Clinical usage of enzyme}

Currently, enzymes have profound application in the clinical section and an important role in diagnosis, prevention, therapeutics, and biochemical analysis. Nowadays, in the therapeutic field, enzymes are used to treat digestive disorders to cancer therapy, also cardiovascular and lysosomal storage diseases. The recent advanced techniques improve the production of human-like therapeutic enzymes by DNA recombination [69].

Amylase has the capability of targeted drug delivery and is also used for "Smart release". Amylase taken from Aspergillus oryzae is used as a digestive aid to treat dyspepsia [70]. For pancreatic disease diagnostics, primarily amylase is used [71]. The exponential increase of multidrug-resistant bacteria happened throughout the year and became a severe threat to human health. These microorganisms form a biofilm which is extracellular polymeric substances (EPS) that helps to attach to the biotic and abiotic surfaces. On successful conjugation of silver nanoparticles (AgNPs) with $\alpha$-amylase, it is used against $K$. pneumoniae and methicillin-resistant Staphylococcus aureus (MRSA). It exhibited antimicrobial activity and reduced the formation of biofilm [72]. The higher levels of $\alpha-$ amylase in the liver could be used to indicate the earlier stages of obesity [73]. The $\alpha$-amylase in the serum can be used as a biomarker for various pancreatic ailments. And $\alpha$-amylase concentration can be used as real-time detection for pancreatic disorders. Millions of people can get benefitted from this affordable procedure [74]. Despite the benefits of kidney transplantation, complications in the post-transplant period affect the long-term allograft. For most kidney transplants, "Delayed graft function (DGF)" is a common complication. It is caused particularly for those who received a kidney transplant from a deceased donor [75]. At 
the earlier stages of DGF, an increase in serum amylase and Resistive index (RI) will occur. DGF can be detected earlier by the serum amylase and RI $>0.7$ after the kidney transplant [76].

Cellulase has a vital clinical application. The bezoars are caused by the presence of partially digested or undigested material in the gastrointestinal tract. It is cured by cellulase, which prevents reintervention also [77,78]. The cellulase-treated wheat bran used in pasta production has comparatively high soluble fibers and a lower glycaemic index than untreated [79]. Keratitis is a serious corneal infection that may cause blindness. The use of contact lenses is the leading risk factor for microbial keratitis. In combination with anti-amoebic compounds, cellulase effectively prevents keratitis, which targets the cyst wall [80,81]. In medical textiles, antibacterial activity was necessary to reduce the bioburden and hospital-acquired infections. The cellulase-treated fabrics were coated with Zinc Oxide $(\mathrm{ZnO})$ nanoparticles, which provide better adhesion, and the antibacterial activity remains even after the multiple washing [82]. The extracts from cellulase-treated microalgae cells show higher toxicity against the benign tumor than lysozyme and other chemical drugs [83].

Protease (Bromelain, chymotrypsin) from Ananas comosus and serum was used to treat edema, inflammation, upper respiratory tract, and ophthalmology diseases. Papain protease is used for the treatment of Thrombotic disorder [84]. Proteolytic activity regulation is a major factor in the clinical application of protease. Cellular receptors, growth factors, and chemokines are regulated by protease through inactivation and activation of gene regulation and intracellular signaling [85]. Protease was also investigated for the nanomedicine approaches to target and treat the tumor, and some fundamental processes were already implemented to treat cancer disease [86]. The maintenance of homeostasis is essential in pathogenic organisms and humans. This can be done by protease enzyme [87].

Lipase enzyme has an excellent pharmaceutical application and diagnostic aids. Especially, it is used for the digestion of fats in humans also for the treatment of lifestyle diseases known as obesity [88,89]. The lipase from Candida rugosa synthesizes lovastatin, a drug that lowers serum cholesterol levels. 4-Methoxyphenyl glycidic acid methyl ester (MPGM) is a key product synthesis from diltiazem hydrochloride is utilized for the coronary vasodilator screened from Serratia marcescens [90]. Enantioselective transesterification and interesterification response by the assistance of lipases have incredible essentialness in the drug industry for specific diacylation and acylation response [91]. Monoacylglycerol lipase is responsible for the pro-tumorigenic or pro-inflammatory effects of the metabolism process [92].

Esterase plays a major role in clinical applications. Cocaine esterase (CocE) is a favorable strategy for treating addiction and overdose cocaine [93]. Leucocyte esterase enzyme is widely found in urine and feces. The strip made by leucocyte esterase plays a major role in periprosthetic joint infection diagnostics [94]. It plays a main role in inflammation reduction, pain relief from arthritis, menstruation, fever, and sunburn. Esterase extracted from Trichosporon brassicae has effective pain-relieving results. Pseudomonas sp. producing esterase enzyme has an ibuprofen-like therapeutic effect [95]. Feruloyl esterase will increase the antioxidant property when it is added to other compounds like fruit juice, and syrup also plays a role in flavor and color [96]. 
Table 1. Different sources of enzymes with allied industrially significant details.

\begin{tabular}{|c|c|c|c|c|c|c|}
\hline Enzyme name & Organism name & Growth media & Specific conditions & Source & $\begin{array}{l}\text { Enzyme } \\
\text { activity }\end{array}$ & Reference \\
\hline \multirow{8}{*}{ AMYLASE } & $\begin{array}{l}\text { Streptomyces } \\
\text { parvulus strain } \\
\text { sankarensis-A10 }\end{array}$ & $\begin{array}{l}\text { Starch agar medium which } \\
\text { has the composition of } \mathrm{g} / \mathrm{L} \text { : } \\
\text { soluble starch } 10.0 \text {, seawater } \\
(50 \% \text { v/v), Meat extract } 3.0 \text {, } \\
\text { agar } 15 \text {. Then, the } \mathrm{pH} \\
\text { adjusted to } 7.0 \pm 0.2\end{array}$ & $\begin{array}{l}\text { Incubated at } 28 \pm 2{ }^{\circ} \mathrm{C} \\
\text { for } 7 \text { days. }\end{array}$ & $\begin{array}{l}\text { Vishakhapatnam coast, Bay of } \\
\text { Bengal (Sediment sample) }\end{array}$ & $\begin{array}{l}25.53 \pm 0.50 \\
\mathrm{U} / \mathrm{ml}\end{array}$ & [97] \\
\hline & $\begin{array}{l}\text { Bacillus subtilis } \\
\text { SUNGB2 }\end{array}$ & $\begin{array}{l}\text { Thermus agar added with } \\
\text { agar, Beef extract, peptone, } \\
\text { yeast extract, and } \mathrm{NaCl} \text {. }\end{array}$ & $\begin{array}{l}\text { Incubated at } 45^{\circ} \mathrm{C} \text { for } \\
24-48 \text { hours. }\end{array}$ & $\begin{array}{l}\text { Dusun Tua Hot Spring, Hulu } \\
\text { Langat, Selangor \& Sungai } \\
\text { Klah Hot Spring, Perak, } \\
\text { Malaysia (Water samples) }\end{array}$ & $22.14 \mathrm{U} / \mathrm{ml}$ & [98] \\
\hline & $\begin{array}{l}\text { Streptomyces sp. Al- } \\
\text { Dhabi-46 }\end{array}$ & Actinomycetes isolation agar & $\begin{array}{l}\text { Incubated at } 28^{\circ} \mathrm{C} \text { for } 7 \\
\text { days. }\end{array}$ & $\begin{array}{l}\text { Jazan, Saudi Arabia (Soil } \\
\text { samples) }\end{array}$ & $\begin{array}{l}241 \pm 18.1 \\
\mathrm{U} / \mathrm{ml}\end{array}$ & [99] \\
\hline & $\begin{array}{l}\text { Bacillus sp. strain SP- } \\
\text { CH7 }\end{array}$ & Horikoshi medium & $\begin{array}{l}\text { Incubated at } 37^{\circ} \mathrm{C} \text { for } \\
72 \text { hours. }\end{array}$ & $\begin{array}{l}\text { Chilika Lake, India (Sediment } \\
\text { samples) }\end{array}$ & $202.857 \mathrm{U} / \mathrm{ml}$ & {$[100]$} \\
\hline & Bacillus sp. Q-164 & Nutrient agar medium & $\begin{array}{l}\text { Incubated at } 37^{\circ} \mathrm{C} \text { for } \\
48 \text { hours. }\end{array}$ & $\begin{array}{l}\text { Vishakhapatnam, Andhra } \\
\text { Pradesh, India (Palm wine) }\end{array}$ & $942 \mathrm{U} / \mathrm{mg}$. & {$[14]$} \\
\hline & $\begin{array}{l}\text { Saccharopolyspora } \\
s p . \text { strain A9 }\end{array}$ & $\begin{array}{l}\text { Glycerol yeast extract agar, } \\
\text { Maltose yeast extract agar, } \\
\text { Glucose asparagine agar, } \\
\text { Starch casein agar medium } \\
\text { containing Starch } \\
\text { (Prepared in artificial } \\
\text { seawater) }\end{array}$ & 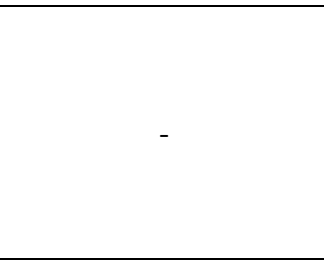 & $\begin{array}{l}\text { Goa, Alibagh, and Mumbai } \\
\text { coastal region of India } \\
\text { (sediment samples) }\end{array}$ & $1640.80 \mathrm{U} / \mathrm{mg}$ & {$[101]$} \\
\hline & $\begin{array}{l}\text { Bacillus tequilensis } \\
\text { TB5 }\end{array}$ & Starch agar medium & $\begin{array}{l}\text { Incubated at } 37^{\circ} \mathrm{C} \text { for } \\
72 \text { hours. }\end{array}$ & $\begin{array}{l}\text { Chandigarh, India (Vegetable } \\
\text { waste) }\end{array}$ & $\begin{array}{l}39.736 \pm 0.296 \\
\mathrm{U} / \mathrm{ml}\end{array}$ & [102] \\
\hline & Bacillus subtilis D19 & Soluble starch & - & Food sample & $0.670 \mathrm{U} / \mathrm{mg}$ & [103] \\
\hline \multirow{2}{*}{ CELLULASE } & $\begin{array}{l}\text { Bacillus } \\
\text { pseudomycoides } \mathrm{Y} 3\end{array}$ & $\begin{array}{l}\text { Carboxyl methylcellulose } \\
\text { (CMC) Agar medium }\end{array}$ & $\begin{array}{l}\text { The plates were } \\
\text { incubated at } 37{ }^{\circ} \mathrm{C} \text { until } \\
\text { sufficient growth. }\end{array}$ & $\begin{array}{l}\text { Rajshahi Sugar Mills Ltd., } \\
\text { Bangladesh (Sugarcane } \\
\text { bagasse) }\end{array}$ & $7.82 \mathrm{IU} / \mathrm{ml}$ & [104] \\
\hline & Bacillus velezensis & $\begin{array}{l}\text { Primary screening medium } \\
\text { (carboxymethylcellulose } \\
\text { sodium, } \mathrm{NaCl} \text {, Tryptone, } \\
\text { yeast powder) }\end{array}$ & $\begin{array}{l}\text { The plates were } \\
\text { incubated at } 37^{\circ} \mathrm{C} \text { for } \\
24 \text { hours. }\end{array}$ & $\begin{array}{l}\text { Lanxi Pig Farm, Suihua City, } \\
\text { Heilongjiang Province, China } \\
\text { (Manure samples) }\end{array}$ & $\begin{array}{l}20.20 \pm 0.74 \\
\mathrm{U} / \mathrm{ml}\end{array}$ & {$[105]$} \\
\hline
\end{tabular}




\begin{tabular}{|c|c|c|c|c|c|c|}
\hline & $\begin{array}{l}\text { Saccharomyces } \\
\text { cerevisiae SCPW } 17\end{array}$ & $\begin{array}{l}\text { Media constituents were } \\
\mathrm{NaNO}_{3}, \mathrm{KH}_{2} \mathrm{PO} \text {, } \\
\mathrm{MgSO}_{4} .7 \mathrm{H}_{2} \mathrm{O}, \mathrm{KCl} \text {, Protease, } \\
\text { peptone, Agar, aqueous } \\
\text { glucose, carboxymethyl } \\
\text { cellulose, and xylan. \& } \\
\text { Ligninase basal medium } \\
\text { supplemented with lignin, } \\
\text { agar. }\end{array}$ & $\begin{array}{l}\text { The } \mathrm{pH} \text { of the medium } \\
\text { was } 6.0 \text { and plates were } \\
\text { incubated at } 28 \pm 2{ }^{\circ} \mathrm{C} \\
\text { for } 3-5 \text { days. }\end{array}$ & $\begin{array}{l}\text { Mushroom farm in Yala Local } \\
\text { Government Area of Cross } \\
\text { River State, Nigeria (Soil } \\
\text { samples) }\end{array}$ & $\begin{array}{l}0.01951 \pm 0.32 \\
\mathrm{U} / \mathrm{mg}\end{array}$ & [106] \\
\hline & $\begin{array}{l}\text { Bacillus } S p . \\
\text { DNH5437 }\end{array}$ & $\begin{array}{l}\text { Tryptic soy agar \& Modified } \\
\text { M-II medium }\left(\mathrm{K}_{2} \mathrm{HPO}_{4},\right. \\
\mathrm{KH}_{2} \mathrm{PO}_{4}, \mathrm{KCl}, \mathrm{NaCl}_{2} \mathrm{NH}_{4} \mathrm{Cl} \text {, } \\
\mathrm{MgSO}_{4} 7 \mathrm{H}_{2} \mathrm{O}, \mathrm{CaCl}_{2} .2 \mathrm{H} 2 \mathrm{O}, \\
\text { peptone, yeast extract, } \\
\text { glucose, agar) }\end{array}$ & $\begin{array}{l}\text { At } 30^{\circ} \mathrm{C} \text { the plates were } \\
\text { incubated and } 37^{\circ} \mathrm{C} \text { for } \\
\text { a month. }\end{array}$ & $\begin{array}{l}\text { Gut sample of } O \text {. coerulescens } \\
\text { collected from North East Iran } \\
\text { (Almond gardens). }\end{array}$ & $9.0 \mathrm{U} / \mathrm{mg}$. & {$[107]$} \\
\hline & $\begin{array}{l}\text { Bacillus licheniformis } \\
\text { NCIM } 5556\end{array}$ & $\begin{array}{l}\text { Basic Liquid Media } \\
\left(\mathrm{KH}_{2} \mathrm{PO}_{4},\left(\mathrm{NH}_{4}\right)_{2} \mathrm{SO}_{4},\right. \\
\mathrm{MgSO}_{4} \cdot 7 \mathrm{H}_{2} \mathrm{O}, \mathrm{FeSO}_{4}, \mathrm{NaCl} \\
\text { \& yeast extract. })\end{array}$ & - & $\begin{array}{l}\text { Rajapur (Western Coastal area) } \\
\text { Ratnagiri District, Maharashtra, } \\
\text { India. (Soil and water samples) }\end{array}$ & $42.99 \mathrm{U} / \mathrm{ml}$ & {$[108]$} \\
\hline & $\begin{array}{l}\text { Aspergillus fumigatus } \\
\text { (CWSF-7) }\end{array}$ & Potato dextrose agar medium & - & $\begin{array}{l}\text { Bhubaneswar, India (Soil } \\
\text { samples) }\end{array}$ & $1.9 \mathrm{U} / \mathrm{ml}$ & [109] \\
\hline & $\begin{array}{l}\text { Bacillus velezensis } \\
\text { ASN1 }\end{array}$ & $\begin{array}{l}\text { Carboxymethyl-cellulose } \\
\text { (CMC) agar medium }\end{array}$ & $\begin{array}{l}\text { For } 48 \text { hours at } 37^{\circ} \mathrm{C} \\
\text { the plates were } \\
\text { incubated. }\end{array}$ & $\begin{array}{l}\text { Barka, Oman, Animal } \\
\text { farmhouse. (Soil samples) }\end{array}$ & $2.42 \mathrm{U} / \mathrm{ml}$ & {$[110]$} \\
\hline & Bacillus subtilis BY-2 & $\begin{array}{l}\text { LB agar medium } \\
\text { supplemented with } 1 \% \mathrm{CMC}\end{array}$ & $\begin{array}{l}\text { The incubated time is } \\
\text { about } 37^{\circ} \mathrm{C} \text { for } 24 \\
\text { hours. }\end{array}$ & $\begin{array}{l}\text { Tibetan pig from Shaanxi } \\
\text { HuaYi Industrial Co., Ltd.; } \\
\text { Tibetan pig breeding base. } \\
\text { (Intestinal samples) }\end{array}$ & $3.56 \mathrm{U} / \mathrm{ml}$. & [111] \\
\hline & $\begin{array}{l}\text { Cladosporium } \\
\text { cladosporioides NS2 }\end{array}$ & Potato dextrose agar medium. & $\begin{array}{l}\text { For } 4 \text { to } 6 \text { days the } \\
\text { plates were incubated at } \\
45^{\circ} \mathrm{C} \text {. }\end{array}$ & $\begin{array}{l}\text { Agriculture field of Banaras } \\
\text { Hindu University, Varanasi, } \\
\text { India. (Rotten wood sample) }\end{array}$ & $0.240 \mathrm{U} / \mathrm{mg}$. & {$[112]$} \\
\hline & $\begin{array}{l}\text { Aneurinibacillus } \\
\text { aneurinilyticus BKT- } \\
9\end{array}$ & Nutrient agar medium & $\begin{array}{l}\text { The medium was } \\
\text { incubated at } 37^{\circ} \mathrm{C} \text {. }\end{array}$ & $\begin{array}{l}\text { Dal lake, Jammu\& Kashmir, } \\
\text { India. (Water samples) }\end{array}$ & 83.1092 U/L. & [113] \\
\hline PPOTEA SF & Vibrio alginolyticus & Skim milk media & $\begin{array}{l}\text { The culture plate } \\
\text { maintained and kept for } \\
\text { incubation for } 21,24 \text {, } \\
27 \text { hrs at } 30^{\circ} \mathrm{C} \text {. }\end{array}$ & $\begin{array}{l}\text { Sediments sample collected } \\
\text { from Pantai Gading mangroves, } \\
\text { North Sumatra, Indonesia. }\end{array}$ & $228.81 \mathrm{U} / \mathrm{ml}$ & [114] \\
\hline РКОIЕАВЕ & $\begin{array}{l}\text { Citricoccus sp. } \\
\text { (KC522120.1) }\end{array}$ & Alkaline agar media & $\begin{array}{l}\text { Specific temperature } 24- \\
48 \mathrm{hrs} \text { was maintained } \\
\text { for the culture plate at } \\
30^{\circ} \mathrm{C} \text {. }\end{array}$ & $\begin{array}{l}\text { Agriculture soil from Regional } \\
\text { Centre of Soil Salinity Research } \\
\text { Institute, Lucknow (U.P.), India. }\end{array}$ & $26.87 \mathrm{U} / \mathrm{ml}$ & [115] \\
\hline
\end{tabular}




\begin{tabular}{|c|c|c|c|c|c|c|}
\hline & $\begin{array}{c}\text { Streptomyces sp. Al- } \\
\text { Dhabi-49 }\end{array}$ & Skimmed milk agar media & $\begin{array}{l}\text { The plates kept at } 28^{\circ} \mathrm{C} \\
\text { for } 5 \text { days up to } \mathrm{pH}-9 \text {. }\end{array}$ & $\begin{array}{l}\text { Soil sample collected from } \\
\text { Dammam marine region. }\end{array}$ & $\begin{array}{l}147.2 \pm 3.6 \\
\mathrm{U} / \mathrm{ml} .\end{array}$ & [116] \\
\hline & Bacillus cereus TSA5 & Nutrient Agar media & $\begin{array}{l}\text { The growth of this } \\
\text { bacteria is high at } 32^{\circ} \mathrm{C} \\
\text { for } 2 \text { days at } \mathrm{pH} 7-8 .\end{array}$ & $\begin{array}{l}\text { Agriculture, compost, and } \\
\text { garden soil }\end{array}$ & $\begin{array}{l}60.41 \quad \pm 0.01 \\
\mathrm{U} / \mathrm{mg} .\end{array}$ & [117] \\
\hline & $\begin{array}{l}\text { Streptomyces sp. Al- } \\
\text { Dhabi- } 82\end{array}$ & Starch casein agar & $\begin{array}{l}\text { To reduce the microbial } \\
\text { growth nalidixic acid } \\
\text { and nystatin-like } \\
\text { antibiotics were added } \\
\text { with the starch casein } \\
\text { agar. }\end{array}$ & $\begin{array}{l}\text { Jazan region of Saudi Arabia } \\
\text { soil. }\end{array}$ & $276 \mathrm{U} / \mathrm{mg}$. & [118] \\
\hline & $\begin{array}{c}\text { Pseudomonas } \\
\text { lundensis DZ845 }\end{array}$ & $\begin{array}{l}\text { Azocasein with phosphate } \\
\text { buffer saline solution and } \\
\text { sodium azide }\end{array}$ & $\begin{array}{l}\text { The specific temperature } \\
\text { maintained for the } \\
\text { samples were } 37^{\circ} \mathrm{C} \text { for } \\
24 \text { hours. }\end{array}$ & $\begin{array}{l}\text { Raw milk samples from New } \\
\text { Zealand. }\end{array}$ & $1.04 \pm 0.02 \mathrm{U} / \mathrm{ml}$ & [119] \\
\hline & $\begin{array}{l}\text { Pseudomonas } \\
\text { aeruginosa }\end{array}$ & $\begin{array}{l}\text { Modified Luria- } \\
\text { Bertani(MLB) agar plates }\end{array}$ & $\begin{array}{l}\text { Additionally, } 10 \% \text { of } \\
\text { toluene and } \\
\text { cyclohexane were added } \\
\text { to the medium. }\end{array}$ & $\begin{array}{l}\text { Crude oil contaminated soil } \\
\text { from Jiangsu province, China. }\end{array}$ & $10,876 \mathrm{U} / \mathrm{ml}$ & [120] \\
\hline & Nesternkonia halobia & casein-yeast plate agar (CYP) & $\begin{array}{l}48 \mathrm{hrs} \text { incubation at } \\
37^{\circ} \mathrm{C} \text { recommended. }\end{array}$ & $\begin{array}{l}\text { Soil or mud from the Lake } \\
\text { Abjata shore, a soda alkaline } \\
\text { lake, Ethiopian Rift valley. }\end{array}$ & $41.2 \mathrm{U} / \mathrm{mg}$ & [121] \\
\hline & $\begin{array}{l}\text { Chromobacterium } \\
\text { violaceum }\end{array}$ & $\begin{array}{l}\text { Using slaughterhouse effluent } \\
\text { which filtered }(500 \mathrm{ml}) \text { and } \\
\text { granulated agar }(7.5 \mathrm{~g}) \\
\text { slaughterhouse effluent agar } \\
\text { was prepared. }\end{array}$ & - & $\begin{array}{l}\text { From Ramanthpur of } \\
\text { Telangana, the slaughter house } \\
\text { effluent was collected }\end{array}$ & $0.1254 \mathrm{U} / \mathrm{ml}$ & {$[122]$} \\
\hline & Haloferax lucentensi & $\begin{array}{l}\text { Tryptone Yeast Extract } \\
\text { (NTYE) agar. }\end{array}$ & $25 \%$ of $\mathrm{NaCl}$ was used & Agro-food waste. & $142.34 \mathrm{U} / \mathrm{ml}$ & {$[123]$} \\
\hline & Bacillus sp. SP II-4 & Skim milk agar. & - & $\begin{array}{l}\text { Saltpan where the strains were } \\
\text { collected which is located in } \\
\text { Kanyakumari }\end{array}$ & $591.04 \mathrm{U} / \mathrm{mg}$. & [124] \\
\hline \multirow{3}{*}{ LIPASE } & $\begin{array}{l}\text { Pseudomonas } \\
\text { aeruginosa }\end{array}$ & Nutrient agar & - & $\begin{array}{l}\text { Soil from mechanic's shop } \\
\text { inverse Forestry College, } \\
\text { Jericho, G.R.A, and Ibadan. }\end{array}$ & $528,540 \mathrm{U} / \mathrm{ml}$ & {$[125]$} \\
\hline & $\begin{array}{l}\text { Pseudomonas } \\
\text { aeruginosa }\end{array}$ & Nutrient broth & $\begin{array}{l}20 \%(\mathrm{v} / \mathrm{v}) \text { to } 40 \%(\mathrm{v} / \mathrm{v}) \\
\text { wastewater added to the } \\
\text { broth. }\end{array}$ & $\begin{array}{l}\text { The wastewater produced from } \\
\text { oil processing plant located in } \\
\text { Tehran. }\end{array}$ & $0.76 \mathrm{U} / \mathrm{ml}$ & [126] \\
\hline & $\begin{array}{l}\text { Pseudomonas } \\
\text { helmanticensis HS6 }\end{array}$ & $\begin{array}{l}\text { Yeast Extract Peptone } \\
\text { Dextrose Agar (YPDA) }\end{array}$ & $\begin{array}{l}\text { This media was } \\
\text { incubated for } 48 \mathrm{hrs} \text { at } \\
30^{\circ} \mathrm{C} \text { to } 37^{\circ} \mathrm{C} \text {. }\end{array}$ & $\begin{array}{l}\text { From Sikkim, the soil sample } \\
\text { were collected above sea level } \\
\text { ranging } 2500 \text { to } 4272 \mathrm{~m} \text {. }\end{array}$ & $179.3 \mathrm{U} / \mathrm{mg}$. & [127] \\
\hline
\end{tabular}




\begin{tabular}{|c|c|c|c|c|c|c|}
\hline & Pseudomonas reinekei & $\begin{array}{l}\text { Inoculated in a medium } \\
\text { containing olive oil is a } \\
\text { carbon source. }\end{array}$ & $\begin{array}{l}\text { Incubated at } 28^{\circ} \mathrm{C} \text { for } \\
72 \mathrm{hrs} \text {. }\end{array}$ & $\begin{array}{l}\text { Wicklow mountains soil from } \\
\text { Ireland. }\end{array}$ & $3.18 \mathrm{I} \mathrm{U} / \mathrm{mg}$. & [128] \\
\hline & $\begin{array}{l}\text { Pria Laot Sabang } 80 \\
\text { (PLS 80) }\end{array}$ & $\begin{array}{l}\text { The solid medium of } 1 / 2 \\
\text { Thermus }(1 / 2 T)\end{array}$ & $\begin{array}{l}\text { Kept for } 70^{\circ} \mathrm{C} \text { for } 18 \\
\text { hrs. }\end{array}$ & $\begin{array}{l}\text { The water sample was collected } \\
\text { from underwater fumaroles in } \\
\text { Aceh Province, Indonesia. }\end{array}$ & $54.2 \mathrm{U} / \mathrm{mg}$. & [129] \\
\hline & $\begin{array}{l}\text { Cystobasidium } \\
\text { oligophagum JRC1 }\end{array}$ & YPD medium & $\begin{array}{l}\text { Incubated at } 30^{\circ} \mathrm{C} \text { for } \\
120 \mathrm{rpm} .\end{array}$ & $\begin{array}{l}\text { Soil collected from Jodhpur is } \\
\text { rich in cellulosic waste. }\end{array}$ & $\begin{array}{l}2.88 \pm 0.166 \\
\mathrm{U} / \mathrm{mg} \text {. }\end{array}$ & [130] \\
\hline & $\begin{array}{l}\text { Staphylococcus } \\
\text { warneri }\end{array}$ & Luria Broth (LB) agar & 型 & $\begin{array}{l}\text { Samples from sludge and } \\
\text { sediment were taken from the } \\
\text { Pulp and Paper Mill of } \\
\text { Uttarakhand. }\end{array}$ & $2.3 \mathrm{U} / \mathrm{mg}$ & {$[131]$} \\
\hline & $\begin{array}{l}\text { Psychrobacter } \\
\text { immobilis }\end{array}$ & Nutrient marine medium 2216 & $\begin{array}{l}\text { Kept for incubation at } \\
4^{\circ} \mathrm{C} \text {. }\end{array}$ & $\begin{array}{l}\text { Seawater collected from Frei } \\
\text { Montalva Base at King George } \\
\text { Island. }\end{array}$ & $1.78 \mathrm{U} / \mathrm{mg}$. & {$[132]$} \\
\hline & $\begin{array}{l}\text { Staphylococcus } \\
\text { saprophyticus }\end{array}$ & Nutrient agar with seawater. & $\begin{array}{l}\text { Plates were incubated at } \\
37^{\circ} \mathrm{C} \text { for } 5 \text { days. }\end{array}$ & $\begin{array}{l}\text { Sediment was collected from } \\
\text { the eastern slope of the Arabian } \\
\text { Sea. }\end{array}$ & $\begin{array}{l}100 \pm 0.121 \\
\mathrm{U} / \mathrm{mg}\end{array}$ & [133] \\
\hline & Aspergillus awamori & $\begin{array}{l}\text { Malt extract (ME) fungal agar } \\
\text { medium. }\end{array}$ & $\begin{array}{l}2 \%(\mathrm{v} / \mathrm{v}) \text { of rice bran oil } \\
\text { was added with the } \\
\text { medium. }\end{array}$ & $\begin{array}{l}\text { The fungal strain from the } \\
\text { Arabian sea of Kerala was } \\
\text { isolated. }\end{array}$ & $123.7 \mathrm{U} / \mathrm{mg}$. & [134] \\
\hline & Fusarium solani FS1 & Potato-dextrose-agar & $\begin{array}{l}\text { Plates were maintained } \\
4^{\circ} \mathrm{C} \text {. }\end{array}$ & $\begin{array}{l}\text { Federal Rural University, Plant } \\
\text { health department, Pernambuco. }\end{array}$ & $0.45 \mathrm{U} / \mathrm{mg}$. & [135] \\
\hline \multirow{7}{*}{ ESTERASE } & Micropolyspora faeni & V8 agar & $\begin{array}{l}\text { Kept incubation at } 40^{\circ} \mathrm{C} \\
\text { for } 6 \text { days. }\end{array}$ & $\begin{array}{l}\text { From London School of } \\
\text { Hygiene and Tropical Medicine } \\
\text { the soil sample were collected. }\end{array}$ & $145 \mathrm{U} / \mathrm{mg}$ & [136] \\
\hline & Bacillus sp. 4 & $\begin{array}{l}\text { Castenholz basal salts } \\
\text { solution }\end{array}$ & $\begin{array}{l}\text { The plates were kept for } \\
24 \mathrm{~h} \text { at } 65{ }^{\circ} \mathrm{C} \text { on a } \\
\text { shaker at } 150 \mathrm{rpm} \text {. }\end{array}$ & $\begin{array}{l}\text { Alangüllü thermal spring } \\
\text { (Aydin, Turkey) }\end{array}$ & $137.77 \mathrm{U} / \mathrm{ml}$ & [137] \\
\hline & $\begin{array}{l}\text { Rhodococcus sp. } \\
\text { LKE- } 021\end{array}$ & Nutrient broth & Using $135 \mathrm{rpm}$ at $60^{\circ} \mathrm{C}$. & $\begin{array}{l}\text { Soil sample from Gangotri, } \\
\text { Uttarakhand, Himalayas. }\end{array}$ & $795.1 \mathrm{U} / \mathrm{mg}$. & [138] \\
\hline & $\begin{array}{l}\text { Rhodococcus sp. } \\
\text { LKE-021 }\end{array}$ & Nutrient broth & $\begin{array}{l}\text { Maintaining in } 60^{\circ} \mathrm{C} \text { for } \\
5 \text { days. }\end{array}$ & $\begin{array}{l}\text { Samples of soil from Gangotri, } \\
\text { Uttarakhand Himalayas. }\end{array}$ & $13.5 \mathrm{U} / \mathrm{mg}$. & {$[25]$} \\
\hline & Ophiostoma piceae & Malt extract -glucose-agar & $\begin{array}{l}\text { This culture kept } \\
\text { incubated at } 26^{\circ} \mathrm{C} \text { and } \\
160 \mathrm{rpm} .\end{array}$ & - & 79 U/mg. & [139] \\
\hline & Pseudomonas putida & Luria-Bertani & $\begin{array}{l}\text { Kept at } 30^{\circ} \mathrm{C} \text { for the } \\
\text { period of } 1 \text { to } 2 \text { days. }\end{array}$ & $\begin{array}{l}\text { Soil from National Taiwan } \\
\text { University and the Taoyuan } \\
\text { District was collected. }\end{array}$ & $\begin{array}{l}1.00 \pm 40 \\
\mathrm{U} / \mathrm{ml}\end{array}$ & {$[140]$} \\
\hline & Trichoderma viride & Nutrient agar & - & $\begin{array}{l}\text { Cultivated area clay in western } \\
\text { Washington was collected. }\end{array}$ & $0.27 \mathrm{U} / \mathrm{mg}$. & [141] \\
\hline
\end{tabular}




\section{Diverse sources of enzyme}

Microorganisms are extensively used in industries as they afford enormous economic ease to industries. Enzymes produced by animals and plants are the most favored source because of their advantages like easy and consistent production. Microbial enzymes are more stable than plant and animal enzymes. Enzymes extracted from microbes are easier to handle and cheaper than plant and animal sources. Microbial enzymes can be produced very effectually by different fermentation techniques in a frugal manner with less time and space demand.

Production of microbial enzymes on a large scale can be done facilely. The samples are being selected from different places to know the qualitative or quantitative nature of the microbes. The growth media of enzymes, conditions, source, and activities are discussed below (Table 1).

\section{Recent process advancements in enzyme technology}

Due to its wide range of applications, amylase production needs to be increased. The important step in the production of enzymes is fermentation technology. For amylase production, submerged fermentation and flask scale fermentation are suggested because of their easy handling and control of greater ecology factors such as $\mathrm{pH}$ and temperature [142,143]. In the submerged fermentation, the maximum activity is analyzed under the optimum condition. Mainly solid-state fermentation is utilized for the production of the metabolites where the purity requirement is low. But also, the down streaming process involved in the SSF is more challenging [144]. To obtain the pure polishing amylase enzyme product, a series of downstream processing is involved. They are ultrafiltration, precipitation, membrane separations, and chromatography techniques [145].

Owing to its industrial application, cellulase manufacture is essential to increase. After the isolation process was carried out, the submerged and solid-state fermentation techniques were utilized to produce cellulase. A study shows that the submerged fermentation was used to increase cellulase enzyme production [146]. Among the various factors involved in the submerged fermentation, the incubation time and temperature play a wide role in cellulase production. But the changes made in submerged fermentation steps and factors can directly affect the production of the enzyme [147,148]. And the purification steps involved here are ammonium sulfate precipitation, centrifugation, dialysis, and chromatography techniques like anion exchange chromatography, gel filtration chromatography [149,150]. After the downstream process, the purity of the product and activity can be analyzed.

Nearly $60 \%$ of the industrial market needs protease enzymes. In order to satisfy, the production needs to be raised. To raise the production needs, sources from various organisms were selected, incubated, and characterized; the protease production using the Submerged fermentation $(\mathrm{SmF})$ or Solid-state fermentation (SSF) step can be carried substrate is liquid, the shake flask fermentation can carry. The shake flask fermentation used for the production of protease in a liquid medium gives a high amount of yield, but it undergoes several purification steps that are difficult to carry out [151,152]. And it also consumes much time. The production of protease can be influenced by $\mathrm{pH}$, temperature, incubation period, and nitrogen concentration. In these above methods, the widely explored process is wheat bran 
mediated SSF because of its easy purification steps and high yield production of protease [153]. Down streaming represents obtaining pure products and product polishing. A wide range of techniques is available to recover the product from the fermented substrate. Protease purification involves several steps and procedures like precipitation, liquid-liquid extraction, chromatography, etc. [154]. To purify protease Diethylaminoethyl cellulose (DEAE-C) column chromatography, gel filtration technique, sodium dodecyl sulfate-polyacrylamide gel electrophoresis (SDS-PAGE) is used. Among these techniques, DEAE-C column chromatography is used tremendously in the past few years to reduce the number of steps involved in purification $[155,156]$.

Lipase versatility makes this a preferable choice for potential application in the pharmaceutical and cosmetics industries. After the strain selection, improvement, and media optimization, fermentation technology was carried out. SmF is mostly used to produce lipase, SSF can also be used rarely. Both SMF and SSF are utilized for the production of largescale bioactive compounds [157]. The nitrogen and carbon concentration, temperature, $\mathrm{pH}$, and dissolved oxygen concentration may influence lipase production [158].

In some cases, immobilized cell culture is also used, but the submerged fermentation is a technique that is employed for the controlled microorganism cultivation in the liquid substrate and target for high yield formation. Recent studies show that the preferred choice for lipase fermentation is SSF because it is cost-effective, simple, easy purification, and eco-friendly [159]. Purification is used to evaluate the enzyme's stability, activity, and commercial value. There are so many techniques for purifying the enzyme-like chromatography, precipitation, flocculation [160]. In this technique, pre-purification steps like ultra-purification and so forth are needed. To overcome the above issues, numerous research works are carried out continuously by industrial researchers. Recent technologies applied for lipase purification are immuno-purification, column chromatography, and hydrophobic interaction chromatography. Hydrophobic interaction chromatography is considered preferable among these techniques because the lipase enzyme is hydrophobic, so lipase purification is achieved by hydrophobic interaction chromatography [161].

Esterase can degrade industrial pollutants, so the enzyme needs to be produced immensely. Fermentation was carried after the preparation of the sample. There are three techniques involved in esterase fermentation. They are submerged, solid-state, and slurry state [162]. Among the above-mentioned three methods, SmF supplement with olive oil and maltose gives high production of esterase enzyme [163]. These crude enzymes are purified using several techniques to obtain the maximum amount of purified esterase enzyme [164]. This purification step includes various processes like ammonium sulfate precipitation, dialysis, acid hydrolysis, and chromatography like gel filtration chromatography, column chromatography [165].

\section{High throughput enzyme assay}

Metagenomics is a technique that studies most of the microbes and the enzyme related to the microbes isolated from an environment. It is a powerful technique for novel gene discovery and provides an opportunity for innovative biotechnological process development. Recently, it was used in the discovery of novel biocatalysts. Up to $99 \%$ of the uncultured bacteria were explored using this technique. Industries depend highly on enzymes for the catalytic process because of the increased reaction rate to several folds. In addition to this, it 
helps in finding superior catalysts for numerous industrial applications [166]. Metagenomics is involved with two ways of approaches for screening the biomolecules. They are sequencebased and functional-based screening of metagenomic libraries. It surpasses the technique that needed the bacteria to be isolated and cultivated. The genomic DNA was isolated directly from samples. It was found to be effective in tapping the metabolic and genetic diversity of complex ecosystems. It helps in the identification of bioactive molecules and novel enzymes [167].

The new approach for efficient amylase activity detection was studied. Glucose oxidase was commonly used in glucose monitoring systems because it is highly specific to glucose. It works based on the principle that the glucose oxidase and the products of amylase interact in the presence of $\mathrm{O}_{2}$, which results in the formation of gluconic acid and $\mathrm{H}_{2} \mathrm{O}_{2}$. Later, the produced $\mathrm{H}_{2} \mathrm{O}_{2}$ can be detected using a kit (Phenol, 4-aminoantipyrine, and peroxidase) and results in red color formation. Further, the absorbance will be measured. Due to the reliability $\&$ applicability of this method, the $\alpha$-amylase activity can successfully determine [168].

The transcriptional regulator-based biosensors can specifically interact with their effectors and produce measurable signals by using the specific products from enzymatic reactions. The Genetic enzyme screening system, massive libraries were utilized by a biosensor to find novel enzymes. The Cellobiose detectible genetic enzyme screening system, a wholecell biosensor, can detect cellulolytic activity and reported that it was a powerful tool because of the high sensitivity in the presence of Cellulosic substrates. The biosensor consists of the regulator and reporter fluorescent protein for detecting the cellulase activity in live cells [169].

The energy transfer-based biosensors were most commonly used to detect proteolytic activity detection in real-time, and they are highly sensitive $\&$ wash-free. As a result of longrange dipole-dipole interactions, energy transfer will occur. So, it can be used in in-vivo conditions. They are used in the early diagnosis of severe diseases [170].

Various studies on lipase enzyme activity prediction were made in recent years. Among those, the lipase activity determined by the aggregation-induced emission-based fluorescence turn-on assay is very notable. The tertraphenylethylene (TPE) derivative with $-\mathrm{COOC}_{6} \mathrm{H}_{13}$ can be hydrolyzed into TPE-COOH, which aggregates easily and has low solubility. A novel fluorescence turns on the probe, which has the ability to detect aggregation-induced emission to visualize the lipase activities. It has high sensitivity and has the application for real-time detection of lipase activity [171].

The enzyme works more in the activities of all organisms, from cell division \& growth to aging \& death. Abnormal activity of enzymes leads to dysfunction and disease. So, it has great significance in the diagnosis and also in the disease treatment. An ultrasensitive technique for detecting T4 polynucleotide kinase (T4 PNK) and telomerase has significant importance. It works based on the primers continuously extending to produce more activation regions, resulting in the initiation of DNase activity of the CRISPR/Cas12a. Then, fluorescent assay ultra-sensitively or visually detects the T4 PNK and telomerase activity. When compared to other methods of detection of these enzymes, it was ultrasensitive, fast, and visual detection of enzyme activity is feasible [172].

The enzyme activity analysis is needed for understanding the pathways associated with disease at the molecular biology level. The construction and implementation of nano kits were helpful in the cost-effective analysis of enzyme activity within the living cells. A nanometersized capillary tube containing the working electrode and the kit components has to be inserted 
into it for protein analysis. For enzyme activity analysis, reversed electrochemical pumping can be used to confine the targeted organelle in the nanocapillary tip [173].

Recent advancements in chemical proteomic methods facilitate enzyme activity detection and quantification. The activity-based proximity ligation (ADPL) method was used to detect and quantify the enzyme activity in single cells. The ADPL platform uses direct conjugation formats, which enables amplification and quantification of active enzymes, even in subcellular resolution [174].

Matrix metalloproteinases-9 (MMP 9) play a vital role in tumor metastasis \& cancer cell invasion. It is commonly used as a potential biomarker for different cancers such as breast cancer, cervical cancer, bone tumor, hepatocellular carcinoma, pancreatic cancer, lung cancer, ovarian cancer, and Osteosarcoma. For the detection of MMP 9, researchers developed an electrode-free electrochemical biosensor. Methylene Blue (MB) was conjugated to the Nterminal of this specific substrate peptide and was immobilized on the Au electrodes. In the presence of MMP 9, it will cleave this peptide. This cleavage results in the release of electroactive MB peptide and changes the electrical tunneling current. It can be used in the detection of MMP 9 [175].

\section{Conclusions}

There is a perpetual hunt for enzymes as it is widely used, particularly in industries. Enzymes are widely used in key fields, such as pharmaceuticals, food processing, and even as substitutes for chemical additives. This review strives to overview amylase, cellulase, protease, lipase, and esterase and their industrial and clinical application. For this review, fonts are collected from various supreme journals and publications. Sources used and the method of production is also described in this review. The reason for using enzymes is that it is a biocatalyst without any side effects and reduces time consumption. Industrial consumers use it every day to create marketable products. Industries are in need of enzymes because of their low processing time. But the industries are facing difficulties in enzyme production and its purification. The recent advanced methods for enzyme production and purification discussed in this review may help researchers and industrialists choose the best, most effective, and suitable techniques for their specific approaches. Nowadays, there is a necessity for new and more versatile enzymes. For the research purpose, this review will give full thought about enzyme production from the microorganism. This allows us to understand the future perspective of enzymes and their importance in the industrials sectors. The further year should see a lot of trends in enzyme and its application.

\section{Funding}

This review received no external funding.

\section{Acknowledgments}

The author gratefully acknowledges the Bioprospecting Research Laboratory, Bannari Amman Institute of technology, for providing an enormous resource and peaceful environment to successfully complete this review. 


\section{Conflicts of Interest}

The authors declare no conflict of interest.

\section{Reference}

1. Kermasha, S.; Michael N. A. E. Enzyme. In Enzyme, Novel Biotechnological Approaches for the Food Industry, $3^{\text {rd }}$ Edition, Editors: Selim Kermasha, Michael N.A. Eskin, Academic press, New York 2021, 5, 1544, https://doi.org/10.1016/B978-0-12-800217-9.00002-2.

2. Matamá, T.; Cavaco-Paulo, A. Enzymatic modification of polyacrylonitrile and cellulose acetate fibres for textile and other applications. Adv. Text. Biotechnol. 2010, 5, 98-131, https://doi.org/10.1533/9780857090232.2.98.

3. Roy, C.; Asim, K. Introduction to enzymes. Sustainable Technologies for Fashion and Textiles, $4^{\text {th }}$ ed.; Elsevier Ltd: West Bengal, India 2019, 75-90, https://doi.org/10.1016/B978-0-08-102867-4.00004-9.

4. Rigoldi, F.; Donini, S.; Redaelli, A.; Parisini, E.; Gautieri, A. Review: Engineering of thermostable enzymes for industrial applications. APL Bioeng. 2018, 2, 011501-17, https://doi.org/10.1063/1.4997367.

5. Silva, C.; Cavaco-Paulo, A.; Nierstrasz, V. A. Enzymatic hydrolysis and modification of core polymer fibres for textile and other applications. Adv. Text. Biotechnol. 2010, 4, 77-97, https://doi.org/10.1533/9780857090232.2.77.

6. Robinson, P. K. Enzymes: principles and biotechnological applications. Essays Biochem. 2015, 59, 1-41, https://doi.org/10.1042/BSE0590001.

7. Petrovic, D.; Risso, V. A.; Kamerlin, S. C. L.; Sanchez-Ruiz, J. M. Conformational dynamics and enzyme evolution, J. R. Soc. Interface 2018, 15, 1-18, https://doi.org/10.1098/rsif.2018.0330.

8. Kumar, J.; Pandey, A.; Singh, S. P. An introduction to enzyme structure dynamics and enzyme catalysis. Biomass, Biofuels, Biochem. 2020, 1, 3-10, https://doi.org/10.1016/b978-0-12-819820-9.00001-6.

9. Bhatia, S. Introduction to enzymes and their applications. Introd. to Pharm. Biotechnol. 2018, 2, 1-29, https://doi.org/10.1088/978-0-7503-1302-5ch1.

10. Kani, P.; Hashemi, T.; Amir Jouya, K.; Abdulkarim Yasin, N.; Nadir, M. Q. S.; Abbas, A. F.; Mohammad Y.; Bing, K.; Rizwan, H. S.; Ali, A. Enzyme immobilization onto the nanomaterials: Application in enzyme stability and prodrug-activated cancer therapy. Int. J. Biol. Macromol. 2020, 143, 665-676, https://doi.org/10.1016/j.ijbiomac.2019.12.064.

11. Vlieghe, P.; Lisowski, V.; Martinez, J.; Khrestchatisky, M. Synthetic therapeutic peptides: science and market. Drug Discov. Today 2010, 15, 40-56, https://doi.org/10.1016/j.drudis.2009.10.009.

12. Aldridge, S. Industry backs biocatalysis for greener manufacturing. Nat. Biotechnol. 2013, 31, 95-96, https://doi.org/10.1038/nbt0213-95.

13. Araújo, R.; Casal, M.; Cavaco-Paulo, A. Application of enzymes for textile fibres processing. Biocatal. Biotransformation 2008, 26, 332-349, https://doi.org/10.1080/10242420802390457.

14. Lakshmi, S. S.; Mahesh, C. H.; Gayatri, K.; Manisha, P.; Aishwarya, K. Statistical optimization of amylase production and its purification from a palm wine isolate Bacillus sp., Q-164. Biocatal. Agric. Biotechnol. 2020, 29, 101-820, https://doi.org/10.1016/j.bcab.2020.101820.

15. Bhatt, K.; Lal, S. R.; Joshi, B. Bioconversion of agriculture wastes to produce $\alpha$ - amylase from Bacillus velezensis KB 2216: Purification and characterization. Biocatal. Agric. Biotechnol. 2020, 28, 101-703, https://doi.org/10.1016/j.bcab.2020.101703.

16. Božić, N.; Rozeboom, H. J.; Lončar, N.; Slavić, M. S.; Janssen, D. B.; Vujčić, Z. Characterization of the starch surface binding site on Bacillus paralicheniformis $\alpha$-amylase. Int. J. Biol. Macromol. 2020, 165, 15291539, https://doi.org/10.1016/j.ijbiomac.2020.10.025.

17. Prasad, S.; Roy, I. Converting Enzymes into Tools of Industrial Importance. Recent Pat. Biotechnol. 2017, 12, 33-56, https://doi.org/10.2174/1872208311666170612113303.

18. Li, Y.; Dandan, T.; Shi, Z.; Yaning, W.; Xu, Y.; Enbo, C.; Bo, H. Preparation of porous starch by $\alpha$-amylasecatalyzed hydrolysis under a moderate electric field. Lwt 2020, 137, 1104-49, https://doi.org/10.1016/j.lwt.2020.110449.

19. Okal, E. J.; Aslam, M. M.; Karanja, J. K.; Nyimbo, W. J. Mini review: Advances in understanding regulation of cellulase enzyme in white-rot basidiomycetes. Microb. Pathog. 2020, 147, 104-410, https://doi.org/10.1016/j.micpath.2020.104410. 
20. Yang, L.; Wei, F.; Huan, Z.; Min, Z.; Zheng, Y.; Lishi, J.; Xin, L. Synergistic effect of ionic liquid and surfactant for enzymatic hydrolysis of lignocellulose by Paenibacillus sp. LLZ1 cellulase. Biomass and Bioenergy 2020, 142, 1057-60, https://doi.org/10.1016/j.biombioe.2020.105760.

21. Zou, G. B.; Dapeng, W.; Ying, Z.; Sichi, X.; Meili, Y.; Zhanshan, W.; Yinmei, Z. Z. Alleviating product inhibition of Trichoderma reesei cellulase complex with a product-activated mushroom endoglucanase. Bioresour. Technol. 2021, 319, 1241-19, https://doi.org/10.1016/j.biortech.2020.124119.

22. Gupta, R.; Beg, Q.; Lorenz, P. Bacterial alkaline proteases: Molecular approaches and industrial applications. Appl. Microbiol. Biotechnol. 2002, 59, 15-32, https://doi.org/10.1007/s00253-002-0975-y.

23. Antonia, M.; Colabone, P.; Baldo, C. Lipase: properties,functions,and Food Applications. In Microbial Enzyme Technology in Food Applications, $1^{\text {st }}$ edition, Editor:1 Ramesh C Ray, Editor 2: Cristina M Rosell, Taylor \& Francis, Boca Raton, United States 2015, 12, 216-242, https://doi.org/10.1201/9781315368405.

24. Treichel, H.; de Oliveira, D.; Mazutti, M.A.; Marco, D. L.; Vladimir Oliveira, J. A Review on Microbial Lipases Production. Food Bioprocess Technol 2010, 3, 182-196, https://doi.org/10.1007/s11947-009-02022.

25. Singh, L.; Sharma, G.; Awasthi, G.; Kumar, L.; Ali, M. I.; Moin, S. Screening, isolation and identification of thermophilic esterase enzyme isolated from Rhodococcus sp: LKE-021. J. Pure Appl. Microbiol. 2019, 13, 1855-1861, https://doi.org/10.22207/JPAM.13.3.63.

26. Bornscheuer, U. T. Microbial carboxyl esterases: Classification, properties and application in biocatalysis. FEMS Microbiol. Rev. 2002, 26, 73-81, https://doi.org/10.1016/S0168-6445(01)00075-4.

27. De Luca, V.; Mandrich, L. Lipases/esterases from extremophiles: main features and potential biotechnological applications. In Physiological and Biotechnological Aspects of Extremophiles, Edition:1, Editors: Sharma, Richa Salwan, Vivek, Elsiver INC, India 2020, 169-181, https://doi.org/10.1016/b978-012-818322-9.00013-7.

28. Lagarde, D. N.; Hong, K. R.; Gilles, W.; Denis, R.; Jean, L.; Hills, G. V.; Thomas, L. F. High-throughput screening of thermostable esterases for industrial bioconversions. Org. Process Res. Dev. 2002, 6, 441-445, https://doi.org/10.1021/op020019h.

29. Boyce, S.; Tipton, K. F. Enzyme Classification and Nomenclature. Food Biochem. Food Process. 2007, 1, 135-154, https://doi.org/10.1002/9780470277577.ch6.

30. Angel, T.; Martíneza, F.; Ruiz-Dueñas, J.; Susana, C.; Ana, S.; Dolores, L.; Henrik, L.; Jesper, V.; Morten, T.; Owik, M. H.; Martin, H. Oxidoreductases on their way to industrial biotransformations. Biotechnol. Adv. 2017, 35, 815-831, https://doi.org/10.1016/j.biotechadv.2017.06.003.

31. Yadav, P.; Sangeeta, K.; Yadav, K.; Dinesh, D.; Yadav, S. Pectin lyase: A review. Process Biochem. Biochem. 2009, 44, 1-10, https://doi.org/10.1016/j.procbio.2008.09.012.

32. Cuesta, S. M.; Rahman, S. A.; Thornton, J. M. Exploring the chemistry and evolution of the isomerases. Proc. Natl. Acad. Sci. U. S. A. 2016, 113, 1796-1801, https://doi.org/10.1073/pnas.1509494113.

33. Martinez Cuesta, S.; Furnham, N.; Rahman, S. A.; Sillitoe, I.; Thornton, J. M. The evolution of enzyme function in the isomerases. Current Opinion in Structural Biology 2014, 26, 121-130, http://dx.doi.org/10.1016/j.sbi.2014.06.002.

34. Samanta, S. T.; Shuzo, D.; Louis, M. F.; Paulette, M.; Yohei, K.; Hisamori, L.; Rich, B.; Ronald J. L.; Vonne, G.Y.; Neamati, N. Expression of protein disulfide isomerase family members correlates with tumor progression and patient survival in ovarian cancer. Oncotarget 2017, 8, 103543-103556, https://doi.org/10.18632/oncotarget.21569.

35. Neifar, S. H.; Hajer, B. M.; Sonia, M.; Monia, B.; Khelifa, I.; Adel, H. J.; Bassem, B. D.; Amel, B. S. A novel thermostable and efficient Class II glucose isomerase from the thermophilic Caldicoprobacter algeriensis: Biochemical characterization, molecular investigation, and application in High Fructose Syrup production. Int. J. Biol. Macromol. 2019, 129, 31-40, https://doi.org/10.1016/j.ijbiomac.2019.01.150.

36. Cornish B. A. Current IUBMB recommendations on enzyme nomenclature and kinetics. Perspect. Sci. 2014, 1, 74-87, https://doi.org/10.1016/j.pisc.2014.02.006.

37. Holliday, G. L.; Rahman, S. A.; Furnham, N.; Thornton, J. M. Exploring the biological and chemical complexity of the ligases. J. Mol. Biol. 2014, 426, 2098-2111, https://doi.org/10.1016/j.jmb.2014.03.008.

38. Manubolu, M.; Goodla, L.; Pathakoti, K.; Malml, K. Enzymes as direct decontaminating agents-mycotoxins. Enzym. Hum. Anim. Nutr. Princ. Perspect. 2018, 16, 313-330, https://doi.org/10.1016/B978-0-12-8054192.00016-2.

39. Porto, S. V.; Luciana, K.; Susan, G. B. P.; Maria, G.; Linsingen, V. T.; Matheus, L. J.; Nelson, V. D.; Kim, 
V.; Jéssica, A. S.; Carlos, R. Classification of enzymes and catalytic properties. Biomass, Biofuels, Biochem. 2020, 2, 11-30, https://doi.org/10.1016/b978-0-12-819820-9.00002-8.

40. Patricia, J.; Khushbu, P.; Dinesh, R. Disorder: Carnitine-acylcarnitine translocase deficiency. In A Quick Guide to Metabolic Disease Testing Interpretation, $2^{\text {nd }}$ Edition, Editors: Patricia Jones, Khushbu Patel, Dinesh Rakheja, Elsevier, British Library Cataloguing-in-Publication Data, United Kingdom 2020, 133-136, https://doi.org/10.1016/B978-0-12-816926-1.00025-0.

41. Hammami, A.; Fakhfakh, N.; Abdelhedi, O.; Nasri, M.; Bayoudh, A. Proteolytic and amylolytic enzymes from a newly isolated Bacillus mojavensis SA: Characterization and applications as laundry detergent additive and in leather processing. Int. J. Biol. Macromol. 2018, 108, 56-68, https://doi.org/10.1016/j.ijbiomac.2017.11.148.

42. Sen, S. K.; Jana, A.; Bandyopadhyay, P.; Das Mohapatra, P.K.; Raut, S. Thermostable amylase production from hot spring isolate Exiguobacterium sp: A promising agent for natural detergents. Sustain. Chem. Pharm. 2016, 3, 59-68, https://doi.org/10.1016/j.scp.2016.04.002.

43. Wang, G.; Xiaofei, K.; Ren, C.; Xiulian, Y.; Geng, S.; Xie, M.; Qiuju, W.; Hua, B. Molecular cloning and characterization of a novel -Amylase from antarctic sea ice bacterium pseudoalteromonas sp. M175 and its primary application in detergent. Biomed Res. Int. 2018, 2018, 1-16, https://doi.org/10.1155/2018/3258383.

44. Al-Ghanayem, A. A.; Joseph, B. Current prospective in using cold-active enzymes as eco-friendly detergent additive. Appl. Microbiol. Biotechnol. 2020, 104, 2871-2882, https://doi.org/10.1007/s00253-020-10429-X.

45. Qiang, W. Z.; Yu, C. H.; Hui, F. M.; Jun, W. Y.; Qiao, J. L.; Hai, J. J. A novel high maltose-forming $\alpha-$ amylase from Rhizomucor miehei and its application in the food industry. Food Chem. 2020, 305, 125-447, https://doi.org/10.1016/j.foodchem.2019.125447.

46. Khemakhem, B.; El Abed, H.; Chakroun, M.; Fendri, I.; Smaoui, S. Functional effects of ice plant amylases on cake and bun quality. Food Biosci. 2019, 29, 142-149, https://doi.org/10.1016/j.fbio.2019.04.008.

47. Roth, E.; Christian, M.; Olga, V. T.; Johan, P. B.; Waterman, S.; Jitka, A.; Antonio, M.; Li-Tianqi, C.; Andersen, G.; Davies, J.; Wilson, K. S. Structural and functional characterization of three novel fungal amylases with enhanced stability and ph tolerance. Int. J. Mol. Sci. 2019, 20, 1-15, https://doi.org/10.3390/ijms20194902.

48. Cripwell, R. A.; Van Zyl W. H.; Viljoen-Bloom, M. Fungal Biotechnology: Fungal Amylases and Their Applications. In Reference Module in Life Sciences, $1^{\text {st }}$ edition, Editor: Shi Pengjun, Elsevier Ltd., Stellenbosch, South Africa 2020, 1-13, https://doi.org/10.1016/b978-0-12-809633-8.21082-0.

49. Kumar D.; Singh, V. Dry - grind processing using amylase corn and superior yeast to reduce the exogenous enzyme requirements in bioethanol production. Biotechnol. Biofuels 2016, 9, 1-12, https://doi.org/10.1186/s13068-016-0648-1.

50. Wood, N. M.; Ian, P. C.; Wilson, P.; David, R. R.; Robertson, K. W.; James, A. W. Ethanol from a biorefinery waste stream: Saccharification of amylase, protease and xylanase treated wheat bran. FOOD Chem. 2015, 198, 125-131, https://doi.org/10.1016/j.foodchem.2015.09.108.

51. Vinod Kumar, N.; Rani, M. E.; Gunaseeli, R.; Kannan, N. D. Paper pulp modification and deinking efficiency of cellulase-xylanase complex from Escherichia coli SD5. Int. J. Biol. Macromol. 2018, 111, 289-295, https://doi.org/10.1016/j.ijbiomac.2017.12.126.

52. Bajaj, M.; Priyanka, R. Cellulase and xylanase synergism in industrial biotechnology. Appl. Microbiol. Biotechnol. 2019, 1, 1-14, https://doi.org/10.1007/s00253-019-10146-0.

53. Wang, X.; Qiang, L.; Shanshan, Y.; Guihua, C.; Jiachuan, J.; Ni, Y. Recycling cellulase towards industrial application of enzyme treatment on hardwood kraft-based dissolving pulp. Bioresour. Technol. 2016, 212, 160-163, https://doi.org/10.1016/j.biortech.2016.04.048

54. Gu, M.; Fang, H.; Gao, Y.; Su, T.; Niu, Y.; Yu, L. Characterization of enzymatic modified soluble dietary fiber from tomato peels with high release of lycopene. Food Hydrocoll. 2020, 99, 105-321, https://doi.org/10.1016/j.foodhyd.2019.105321.

55. Ademakinwa A. N.; Agboola, F. K. Kinetic and thermodynamic investigations of cell-wall degrading enzymes produced by Aureobasidium pullulans via induction with orange peels : application in lycopene extraction. Prep. Biochem. Biotechnol. 2019, 1-12, https://doi.org/10.1080/10826068.2019.1650375.

56. Cheng, Y.; Li, Z.; Xianmei, H.; Li, C.; Zhaofeng, L.; Gu, Z. Title: Characterisation of Physicochemical and Functional Properties of Soluble Dietary Fibrefrom Potato Pulp Obtained by Enzyme-assisted Extraction. Int. J. Biol. Macromol. 2017, 101, 1-42, https://doi.org/10.1016/j.ijbiomac.2017.03.156.

57. Barzkar, N. Marine microbial alkaline protease: recent developments in biofilm $\mathrm{n}$ ideal choice for industrial 
application. Int. J. Biol. Macromol. 2020, 161, 1216-1229, https://doi.org/10.1016/j.ijbiomac.2020.06.072.

58. Fang, J.; Zhen, Y.; Yang, C. Z.; Juan, D. G. C. Keratinolytic protease : a green biocatalyst for leather industry. Appl. Microbiol. Biotechnol. 2017, 101, 7771-7779, https://doi.org/10.1007/s00253-017-8484-1.

59. Cao, H.; Shan, S.; Jinzhi, L. F.; Wang, K. L.; Yanchun, L.; Yu, L.; Liu, B. Improving characteristics of biochar produced from collagen-containing solid wastes based on protease application in leather production. Waste Manag. 2020, 105, 531-539, https://doi.org/10.1016/j.wasman.2020.02.043.

60. Gurumallesh, P.; Alagu, B.; Kamalini, R.; Muthusamy, S. International Journal of Biological Macromolecules A systematic reconsideration on proteases. Int. J. Biol. Macromol. 2019, 128, 254-267, https://doi.org/10.1016/j.ijbiomac.2019.01.081.

61. Philipps, W. P. Proteases-human food. In Enzyme in Human and Animal Nutrition, 1st Edition, Kumar, Carlos Simões Nunes and Vikas, Elsevier Inc., United States 2018, 267-277, https://doi.org/10.1016/B978-0-12805419-2.00013-7.

62. Guo, H.; Yujie, T.; Tao, Y.; Peng, W.; Yaru, R.; Yaxin, Y.; Bin, L. High-level expression and characterization of a novel aspartic protease from Talaromyces leycettanus JCM12802 and its potential application in juice clarification. Food Chem. 2019, 281, 197-203, https://doi.org/10.1016/j.foodchem.2018.12.096.

63. Ismail, A. R.; Baek, K. H. Lipase immobilization with support materials, preparation techniques, and applications: Present and future aspects. Int. J. Biol. Macromol. 2020, 163, 1624-1639, https://doi.org/10.1016/j.ijbiomac.2020.09.021.

64. Nomaguchi, Y.; Tatsuhiro, M.; Liang, T.; Yue, Y.; Tomoko, A.; Tanaka, T. Comprehensive analysis of triacylglycerol lipases in the oleaginous diatom Fistulifera solaris JPCC DA0580 with transcriptomics under lipid degradation. J. Biosci. Bioeng. 2018, 1-8, https://doi.org/10.1016/j.jbiosc.2018.03.003.

65. Yu, Z. Z.; Huiwen, F.; Xuanhe, L.; Xu, G.; Qiucui, Y.; Tingting, L. X. Immobilization of esterase SulE in cross-linked gelatin/chitosan and its application in remediating soils polluted with tribenuron-methyl and metsulfuron-methyl. Process Biochem. 2020, 98, 217-223, https://doi.org/10.1016/j.procbio.2020.08.014.

66. Tsuboi, K.; Shun, T.; Takumi, Y. T.; Kitamoto, H. High-throughput method for the evaluation of esterase activity in soils. J. Microbiol. Methods 2018, 146, 22-24, https://doi.org/10.1016/j.mimet.2018.01.009.

67. Maester, D. M.; Thaís, C. P.; Mariana, R. S.; Machado, E. G.; Balan, A. G.; Eliana, L. Characterization of EST3 : a metagenome-derived esterase with suitable properties for biotechnological applications. Appl. Microbiol. Biotechnol. 2016, 100, 5815-5827, https://doi.org/10.1007/s00253-016-7385-z.

68. Sanati, A. J.; Mahsa, R.; Keyvan, K.; Fathallah, K.; Mashid, S. S. M. A review on recent advancements in electrochemical biosensing using carbonaceous nanomaterials. Microchim. Acta 2019, 186, 186-773, https://doi.org/10.1007/s00604-019-3854-2.

69. Kumar, S. S.; Sabu, A. Fibrinolytic enzymes for thrombolytic therapy. Advances in Experimental Medicine and Biology 2019, 1148, 345-381, https://doi.org/10.1007/978-981-13-7709-9_15.

70. Vachher, M.; Sen, A.; Kapila, R.; Nigam, A. Microbial therapeutic enzymes: A promising area of biopharmaceuticals. Current Research in Biotechnology 2021, 3, 195-208, https://doi.org/10.1016/j.crbiot.2021.05.006.

71. Logie, J. J.; Cox, M.; Sharkey, J.; Williams, A. A multidisciplinary approach to an unusual cause of hyperamylasaemia. BMJ Case Reports 2015, 2015, 1-3, https://doi.org/10.1136/bcr-2015-209780.

72. Abeleda, H. E. P.; Javier, A. P.; Murillo, A. Q. M.; Baculi, R. Q. Alpha-amylase conjugated biogenic silver nanoparticles as innovative strategy against biofilm-forming multidrug resistant bacteria. Biocatal. Agric. Biotechnol. 2020, 29, 1017-84, https://doi.org/10.1016/j.bcab.2020.101784.

73. Mojbafan, M. A.; Zohreh, A.; Mahsa, M. M.; Mahdi, Y. P. L.; Bagher, E. H.; Azadehkbar, F.; Mojtaba, F. Liver alpha-amylase gene expression as an early obesity biomarker. Pharmacol. Reports 2017, 69, 229-234, https://doi.org/10.1016/j.pharep.2016.11.001.

74. Bhattacharjee, M.; Middya, S.; Escobedo, P.; Chaudhuri, J.; Bandyopadhyay, D.; Dahiya, R. Microdroplet based disposable sensor patch for detection of $\alpha$-amylase in human blood serum. Biosens. Bioelectron. 2020, 165, 1123-33, https://doi.org/10.1016/j.bios.2020.112333.

75. Wu, W. K.; Famure, O.; Li, Y.; Kim, S. J. Delayed graft function and the risk of acute rejection in the modern era of kidney transplantation. International society of Nephrolog, 2015, 1, 1-8., https://doi.org/10.1038/ki.2015.190.

76. Comai, G. B.; Olga, C.; Vania, C.; Valeria, A.; Andrea, B.; Seidju, C.; Irene, C.; Maria, M.; Gaetano, L. A. Increase in Serum Amylase and Resistive Index After Kidney Transplant Are Biomarkers of Delayed Graft Function. In-vivo 2018, 402, 397-402, https://doi.org/10.21873/invivo.11252. 
77. Pinos, N.; Moreno-Merino, S.; Congregado, M. Phytobezoar by aloe vera as long term complication after oesophagectomy resolved using cellulase. Int. J. Surg. Case Rep. 2015, 13, 37-39, https://doi.org/10.1016/j.ijscr.2015.05.008.

78. Reyes-Mondragón, A. L.; Canel-Paredes, A.; Martìnez-Granados, R. J.; Salazar-Mejía, C. E.; HernándezBarajas, D.; Vidal-Gutiérrez, O. Bezoar as a cause of intestinal obstruction as the first manifestation of duodenal adenocarcinoma. Med. Clin. Pract., 2020, 3, 1001-44, https://doi.org/10.1016/j.mcpsp.2020.100144.

79. Nguyen, S. N.; Ngo, T. C.; Tran, T. T.; Nguyet, N. M.; Man Le, V. V. Pasta from cellulase-treated wheat bran and durum semolina: Effects of vital gluten addition and/or transglutaminase treatment. Food Biosci. 2020, 38, 1007-82, https://doi.org/10.1016/j.fbio.2020.100782.

80. Brown, L.; Leck, K. A.; Gichangi, M.; Burton, M. J.; Denning, D. W. The global incidence and diagnosis of fungal keratitis. Lancet Infect. Dis. 2020, 3099, 1-9, https://doi.org/10.1016/S1473-3099(20)30448-5.

81. Abjani, F.; Khan, N. A.; Jung, S. Y.; Siddiqui, R. Status of the effectiveness of contact lens disinfectants in Malaysia against keratitis-causing pathogens. Exp. Parasitol. 2017, 183, 187-193, https://doi.org/10.1016/j.exppara.2017.09.007.

82. Petkova, P.; Francesko, A.; Perelshtein, I.; Gedanken, A.; Tzanov, T. Simultaneous sonochemical-enzymatic coating of medical textiles with antibacterial $\mathrm{ZnO}$ nanoparticles. Ultrason. Sonochem. 2016, 29, 244-250, https://doi.org/10.1016/j.ultsonch.2015.09.021.

83. Jabeen, A. R.; Brandon, H.; Soleiman, A.; Salman, D.; Naeema, A. B.; Sinan, A. Z. S.; Effect of Enzymatic pre-treatment of microalgae extracts on their anti-tumor activity. Biomed. J. 2017, 40, 339-346, https://doi.org/10.1016/j.bj.2017.10.003.

84. Kunamneni, A.; Ogaugwu, C.; Goli, D. Enzymes as therapeutic agents. Enzym. Hum. Anim. Nutr. Princ. Perspect. 2018, 15, 301-312, https://doi.org/10.1016/B978-0-12-805419-2.00015-0.

85. Craik, C. S.; Page, M. J.; Madison, E. L. Proteases as therapeutics. Biochemical journal 2011, 16, 1-16, https://doi.org/10.1042/BJ20100965.

86. Cogo, F.; Williams, R.; Burden, R. E.; Scott, C. J. Application of nanotechnology to target and exploit tumour associated proteases. Biochimie 2019, 166, 112-131, https://doi.org/10.1016/j.biochi.2019.04.021.

87. Tyndall, J. D. A.; Huston, W. M.; Gamble, A. B. Proteases and protease inhibitors in infectious diseases. Medicina Clinica Practica 2017, 38, 1295-1331, https://doi.org/10.1002/med.21475.

88. Jawed, A. S.; Kohli, G.; Sumera, S.; Haque, A.; Prasad, S.; Paul, R. D. Therapeutic role of lipases and lipase inhibitors derived from natural resources for remedies against metabolic disorders and lifestyle diseases. South African J. Bot. 2018, 01999, 1-8, https://doi.org/10.1016/j.sajb.2018.04.004.

89. Rajan, L.; Palaniswamy, D.; Mohankumar, S. K. Targeting Obesity with plant-derived pancreatic lipase inhibitors: A comprehensive review. Pharmacol. Res. 2020, 155, 104-681, https://doi.org/10.1016/j.phrs.2020.104681.

90. Matsumae, H.; Furui, M.; Shibatani, T. Lipase-catalyzed asymmetric hydrolysis of 3-phenylglycidic acid ester, the key intermediate in the synthesis of diltiazem hydrochloride. Journal of Fermentation and Bioengineering 1993, 75, 93-98, https://doi.org/10.1016/0922-338X(93)90216-U.

91. Vishnoi, N.; Dixit, S.; Mishra, J. Microbial Lipases and Their Versatile Applications. Microb. Enzym. Roles Appl. Ind. 2020, 8, 207-230, https://doi.org/10.1007/978-981-15-1710-5_8.

92. Gil-ordóñez, A.; Martín-fontecha, M.; Ortega-gutiérrez, S.; López-rodríguez, M. L. Monoacylglycerol lipase (MAGL) as a promising therapeutic target. Biochem. Pharmacol. 2018, 1, 1-66, https://doi.org/10.1016/j.bcp.2018.07.036.

93. Narasimhan, D. L.; Macdonald, J.; Brim, R.; Ko, M.; Landry, D. W.; Woods, J. H.; Sunahara, R. K.; Zhan, C. Thermostable Variants of Cocaine Esterase for Long-Time Protection against Cocaine Toxicity. Molecular Pharmacology 2009, 75, 318-323, https://doi.org/10.1124/mol.108.049486.

94. Zheng, Q.; Zhang, G. Application of leukocyte esterase strip test in the screening of periprosthetic joint infections and prospects of high-precision strips. Arthroplasty 2020, 2, 34-70, http://doi.org/10.1186/s42836020-00053-5.

95. Lai, O. M.; Lee, Y. Y.; Phuah, E. T.; Akoh, C. C. Lipase/Esterase: Properties and industrial applications. In Encyclopedia of Food Chemistry, $1^{\text {st }}$ edition, Editors: Beddows, Caitlin, Elsevier, United States 2018, 158167, https://doi.org/10.1016/B978-0-08-100596-5.21640-5.

96. Swamy, P.; Govindaswamy, V. Therapeutical properties of ferulic acid and bioavailability enhancement through feruloyl esterase. J. Funct. Foods 2015, 17, 657-666, https://doi.org/10.1016/j.jff.2015.06.013. 
97. Shaik, M.; Girija, S. G.; Iswarya, M.; Rajitha, P. Isolation and characterization of bioactive metabolites producing marine Streptomyces parvulus strain sankarensis-A10. J. Genet. Eng. Biotechnol. 2017, 15, 8794, https://doi.org/10.1016/j.jgeb.2017.02.004.

98. Msarah, M. J.; Ibrahim, I.; Hamid, W. S.; Aidil, A. A. Optimisation and production of alpha amylase from thermophilic Bacillus spp. and its application in food waste biodegradation. Heliyon 2020 6, e041-83, https://doi.org/10.1016/j.heliyon.2020.e04183.

99. Al-Dhabi, N. A.; Esmail, G. A.; Ghilan, A. K. M.; Arasu, M. V.; Duraipandiyan, V.; Ponmurugan, K. Isolation and purification of starch hydrolysing amylase from Streptomyces sp. Al-Dhabi-46 obtained from the Jazan region of Saudi Arabia with industrial applications. J. King Saud Univ. - Sci. 2020, 32, 1226-1232, https://doi.org/10.1016/j.jksus.2019.11.018.

100.Priyadarshini, S.; Ray, P. Exploration of detergent-stable alkaline $\alpha$-amylase AA7 from Bacillus sp strain SPCH7 isolated from Chilika Lake. Int. J. Biol. Macromol., 2019, 140, 825-832, https://doi.org/10.1016/j.ijbiomac.2019.08.006.

101. Chakraborty, L. S.; Khopade, A.; Biao, R.; Jian, W.; Liu, X. Y.; Mahadik, K.; Chopade B. Z. Characterization and stability studies on surfactant, detergent and oxidant stable $\alpha$-amylase from marine haloalkaliphilic Saccharopolyspora sp. A9. J. Mol. Catal. B Enzym., 2011, 68, 52-58, https://doi.org/10.1016/j.molcatb.2010.09.009.

102.Paul, J. S.; Beliya, E.; Tiwari, S.; Patel, K.; Gupta, N.; Jadhav, S. K. Production of biocatalyst $\alpha$-amylase from agro-waste 'rice bran' by using Bacillus tequilensis TB5 and standardizing its production process. Biocatal. Agric. Biotechnol. 2020, 26, 101-648, https://doi.org/10.1016/j.bcab.2020.101648.

103.Almanaa, T. N.; Vijayaraghavan, P.; Alharbi, N. S.; Kadaikunnan, S.; Khaled, J .M.; Alyahya, S. A. Solid state fermentation of amylase production from Bacillus subtilis D19 using agro-residues. J. King Saud Univ. - Sci. 2020, 32, 1555-1561, https://doi.org/10.1016/j.jksus.2019.12.011.

104.Jabin, T.; Naher, K.; Uddin, S. Fermentation optimization of cellulase production from sugarcane bagasse by Bacillus pseudomycoides and molecular modeling study of cellulase. Curr. Res. Microb. Sci. 2020, 2, 100013, https://doi.org/10.1016/j.crmicr.2020.100013.

105.Li, F. X.; Yingjie, G.; Xiang, S.; Mingxu, S.; Changchao, N.; Yan, D. S.; Anshan, S. Screening of cellulose degradation bacteria from Min pigs and optimization of its cellulase production. Electron. J. Biotechnol. 2020, 48, 29-35, https://doi.org/10.1016/j.ejbt.2020.09.001.

106.Amadi, O.; Egong, C.; Egong, J.; Nwagu, T.; Okpala, N.; Gloria, O.; Chukwudi, O.; Chukwu, G.; Okolo, C.; Bartholomew, N.; Agu, R.; Moneke, C.; Anene, N. Process optimization for simultaneous production of cellulase, xylanase and ligninase by Saccharomyces cerevisiae SCPW 17 under solid state fermentation using Box-Behnken experimental design. Heliyon 2020, 6, e045-66, https://doi.org/10.1016/j.heliyon.2020.e04566.

107.Hatefi, A.; Makhdoumi, A.; Asoodeh, A.; Mirshamsi, O. Characterization of a bi-functional cellulase produced by a gut bacterial resident of Rosaceae branch borer beetle, Osphranteria coerulescens (Coleoptera: Cerambycidae). Int. J. Biol. Macromol. 2017, 103, 158-164, https://doi.org/10.1016/j.ijbiomac.2017.05.042.

108. Shajahan, S.; Moorthy, I. G.; Sivakumar, N.; Selvakumar, G. Statistical modeling and optimization of cellulase production by Bacillus licheniformis NCIM 5556 isolated from the hot spring, Maharashtra, India, J. King Saud Univ. - Sci. 2017, 29, 302-310, https://doi.org/10.1016/j.jksus.2016.08.001.

109. Mohapatra, S.; Padhy, S.; Das Mohapatra, P. K.; Thatoi, H. N. Enhanced reducing sugar production by saccharification of lignocellulosic biomass, Pennisetum species through cellulase from a newly isolated Aspergillus fumigatus. Bioresour. Technol. 2018, 1, 1-34, https://doi.org/10.1016/j.biortech.2018.01.023.

110. Sadasivan, A.; Al-battashi, H.; Al-akzawi, A.; Annamalai, N.; Gujarathi, A. Waste office paper : A potential feedstock for cellulase production by a novel strain Bacillus velezensis ASN1. Waste Manag. 2018, 79, 491500, https://doi.org/10.1016/j.wasman.2018.08.014.

111.Yang, W. M.; Fanxu, P.; Jiayin, H.; Peng, F.; Fang, M.; Li, C. B. Electronic Journal of Biotechnology Isolation and identification of a cellulolytic bacterium from the Tibetan pig's intestine and investigation of its cellulase production. Electronic Journal of Biotechnology 2014, 17, 262-267, https://doi.org/10.1016/j.ejbt.2014.08.002.

112. Srivastava, N.; Elgorban, A. M.; Mishra, P. K.; Marraiki, N. Environmental Technology \& Innovation Enhance production of fungal cellulase cocktail using cellulosic waste. Environ. Technol. Innov. 2020, 19, 1009-49, https://doi.org/10.1016/j.eti.2020.100949.

113.Ahmad, T. S.; Anshula, G.; Gaganjot, M.; Sheikhan, S. Kaur.; Baljinder, P.; Bilal, A. A. Response surface optimization of cellulase production from Aneurinibacillus aneurinilyticus BKT-9: An isolate of urban 
Himalayan freshwater. Saudi J. Biol. Sci. 2020, 1-11, https://doi.org/10.1016/j.sjbs.2020.04.036.

114. Mamangkey, J.; Suryanto, D.; Munir, E.; Mustopa, A. Z.; Sibero, M. T.; Mendes, L. W.; Hartanto, A.; Taniwan, S.; Ek-Ramos, M. J.; Harahap, A.; Verma, A.; Trihatmoko, E.; Putranto, W. S.; Pardosi, L.; Rudia, La O. A. P. Isolation and enzyme bioprospection of bacteria associated to Bruguiera cylindrica, a mangrove plant of North Sumatra, Indonesia. Biotechnology Reports 2021, 30, e006-17, https://doi.org/10.1016/j.btre.2021.e00617.

115. Verma, J.; Pandey, S. Characterization of partially purified alkaline protease secreted by halophilic bacterium Citricoccus sp. isolated from agricultural soil of northern India. Biocatalysis and Agricultural Biotechnology 2019, 17, 605-612, https://doi.org/10.1016/j.bcab.2019.01.020.

116. Al-Dhabi, N.; Esmail, Galal A.; Ghilan, A. K.; M.; Arasu, M. V. Isolation and screening of Streptomyces sp. Al-Dhabi-49 from the environment of Saudi Arabia with concomitant production of lipase and protease in submerged fermentation. Saudi Journal of Biological Sciences 2020, 27, 474-479, https://doi.org/10.1016/j.sjbs.2019.11.011.

117.Thomas, N. N.; Archana,V.; Shibina, S.; B. T. Edwin. Isolation and characterization of a protease from Bacillus sps. Mater. Today Proc. 2020, 41, 685-691, https://doi.org/10.1016/j.matpr.2020.05.435.

118. Abdullah, A. N.; Ali Esmail, G.; Mohammed Ghilan, A. K.; Valan Arasu, M.; Duraipandiyan, V.; Ponmurugan, K. Characterization and fermentation optimization of novel thermo stable alkaline protease from Streptomyces sp. Al-Dhabi-82 from the Saudi Arabian environment for eco-friendly and industrial applications. J. King Saud Univ. - Sci. 2020, 32, 1258-1264, https://doi.org/10.1016/j.jksus.2019.11.011.

119.Zhang, D.; Palmer, J.; Teh, K. H.; Calinisan, M. M. A.; Flint, S. Milk fat influences proteolytic enzyme activity of dairy Pseudomonas species. Int. J. Food Microbiol. 2020, 320, 108-543, https://doi.org/10.1016/j.ijfoodmicro.2020.108543.

120.Tang, X. Y.; Pan, Y.; Li, S.; He, B. F. Screening and isolation of an organic solvent-tolerant bacterium for high-yield production of organic solvent-stable protease. Bioresour. Technol. 2008, 99, 7388-7392, https://doi.org/10.1016/j.biortech.2008.01.030.

121.Gessesse, A.; Hatti-Kaul, R.; Gashe, B. A.; Mattiasson, B. Novel alkaline proteases from alkaliphilic bacteria grown on chicken feather. Enzyme Microb. Technol. 2003, 32, 519-524, https://doi.org/10.1016/S01410229(02)00324-1.

122.Ramakodi, M P.; Santhosh, N.; Pragadeesh, T.; Mohan, S. V.; Basha, S. Production of protease enzyme from slaughterhouse effluent: An approach to generate value-added products from waste. Bioresour. Technol. Reports 2020, 12, 1005-52, https://doi.org/10.1016/j.biteb.2020.100552.

123. Gaonkar, S. K.; Furtado, I. J. Valorization of low-cost agro-wastes residues for the maximum production of protease and lipase haloextremozymes by Haloferax lucentensis GUBF-2 MG076078. Process Biochem. 2020, 1, 1-41, https://doi.org/10.1016/j.procbio.2020.10.019.

124. Rejisha, R. P.; Murugan, M. Materials Today: Proceedings Alkaline protease production by halophilic Bacillus sp . strain SP II-4 and characterization with special reference to contact lens cleansing. Mater. Today Proc. 2020, 45, 1757-1760, https://doi.org/10.1016/j.matpr.2020.08.624.

125.Ilesanmi, O. I.; Adekunle, A. E.; Omolaiye, J. A.; Olorode, E. M.; Ogunkanmi, A. L. Isolation, optimization and molecular characterization of lipase producing bacteria from contaminated soil. Sci. African 2020, 8, e002-79, https://doi.org/10.1016/j.sciaf.2020.e00279.

126.Mobarak-Qamsari, E.; Kasra-Kermanshahi, R.; Moosavi-Nejad, Z. Isolation and identification of a novel, lipase-producing bacterium, pseudomnas aeruginosa KM110. Iran. J. Microbiol. 2011, 3, 92-98, https://doi.org/10.5281/zenodo.3249860.

127. Chiring, L.; Chourasia, R.; Kumari, M.; Krishnan, T.; Sahoo, D.; Parameswaran, B. Bioresource Technology Production and characterisation of lipase for application in detergent industry from a novel Pseudomonas helmanticensis HS6. Bioresource Technology 2020, 309, 123-352, https://doi.org/10.1016/j.biortech.2020.123352.

128.Priyanka, P.; Kinsella, G.; Henehan, G. T.; Ryan, B. J. Isolation, purification and characterization of a novel solvent stable lipase from Pseudomonas reinekei. Protein Expr. Purif. 2019, 153, 121-130, https://doi.org/10.1016/j.pep.2018.08.007.

129.Febriani, N.; Aura, P.; Kemala, N.; Saidi, T.; Iqbalsyah, M. Novel thermostable lipase produced by a thermohalophilic bacterium that catalyses hydrolytic and transesterification reactions. Heliyon 2020, 6, e04-520, https://doi.org/10.1016/j.heliyon.2020.e04520.

130. Vyas, S.; Chhabra, M. Isolation, identification and characterization of Cystobasidium oligophagum JRC1: A 
cellulase and lipase producing oleaginous yeast. Bioresour. Technol. 2017, 223, 250-258, https://doi.org/10.1016/j.biortech.2016.10.039.

131.Tripathi, R.; Singh, J.; Bharti, R. K.; Thakur, I. S. Isolation, purification and characterization of lipase from microbacterium sp. and its application in biodiesel production. Energy Procedia 2014, 54, 518-529, https://doi.org/10.1016/j.egypro.2014.07.293.

132.Parra, L. P.; Reyes, F.; Acevedo, J. P.; Salazar, O.; Andrews, B. A.; Asenjo, J. A. Cloning and fusion expression of a cold-active lipase from marine Antarctic origin. Enzyme Microb. Technol. 2008, 42, 371377, https://doi.org/10.1016/j.enzmictec.2007.11.003.

133.Farha, A. K.; TR, T.; Purushothaman, A.; Salam, J. A.; Hatha, A. M. Phylogenetic diversity and biotechnological potentials of marine bacteria from continental slope of eastern Arabian Sea. J. Genet. Eng. Biotechnol. 2018, 16, 253-258, https://doi.org/10.1016/j.jgeb.2018.06.002.

134.Basheer, S. M.; Chellappan, S.; Beena, P. S.; Sukumaran, R. K.; Elyas, K. K.; Chandrasekaran, M. Lipase from marine Aspergillus awamori BTMFW032: Production, partial purification and application in oil effluent treatment. N. Biotechnol. 2011, 28, 627-638, https://doi.org/10.1016/j.nbt.2011.04.007.

135.Maia, M. M. D.; Heasley, A.; Morais, M. M. C.; Melo, E. H. M.; Jr, M. A. M.; Ledingham, W. M.; Filho, J. L. L. Effect of culture conditions on lipase production by Fusarium solani in batch fermentation. Bioresource Technology 2001, 76, 23-27, https://doi.org/10.1016/S0960-8524(00)00079-1.

136. Bannerman, E. N.; Nicolet, J. Isolation and characterization of an enzyme with esterase activity from Micropolyspora faeni. Appl. Environ. Microbiol. 1976, 32, 138-144, https://doi.org/10.1128/aem.32.1.138144.1976.

137.Ateşlier, Z. B. B.; Metin, K. Production and partial characterization of a novel thermostable esterase from a thermophilic Bacillus sp. Enzyme and Microbial Technology 2006, 38, 628-635, https://doi.org/10.1016/j.enzmictec.2005.07.015.

138.Singh, S.; Lekha, S.; Gaurav, S.; Asha, A.; Gyanendra, K.; Lokendra, A.; Mohammad, I.; Moin, S. Purification, Isolation, and Characterization of Esterase from Rhodococcus sp. 1Ke-021. J. Pure Appl. Microbiol. 2020, 14, 1387-1395, https://doi.org/10.22207/JPAM.14.2.36.

139.Calero-Rueda, O.; Plou, F. J.; Ballesteros, A.; Martínez, A. T.; Martínez, M. J. Production, isolation and characterization of a sterol esterase from Ophiostoma piceae. Biochim. Biophys. Acta - Proteins Proteomics 2002, 1599, 28-35, https://doi.org/10.1016/S1570-9639(02)00378-3.

140.Peng, Y.H.; Hsin Shih, Y.; Lai, Y. C.; Liu, Y. Z.; Liu, Y. T.; Lin, N. C. Degradation of polyurethane by bacterium isolated from soil and assessment of polyurethanolytic activity of a Pseudomonas putida strain. Environ. Sci. Pollut. Res. 2014, 21, 9529-9537, https://doi.org/10.1007/s11356-014-2647-8.

141. Satyanarayana, T.; Getzin, L. W. Properties of a Stable Cell-Free Esterase from Soil. Biochemistry 1973, 12 , 1566-1572, https://doi.org/10.1021/bi00732a016.

142. Rengasamy, S. Isolation, Screening And Determination Of A -Amylase Activity From Marine Streptomyces Species. Int. J. Pharm. Pharm. Sci. 2018, 10, 122-127, https://doi.org/10.22159/ijpps.2018v10i4.24447.

143.Singh, R.; Sharma, D. C.; Gupta, M. K. Optimization of critical process parameters for amylase production by Bacillus sp. using statistical approach (RSM). Journal of Microbiology and Biotechnology Research 2017, 7, 7-15, https://doi.org/10.24896/jmbr.2017732.

144.Kumar, J.; Vinod, A.; Vivek, S.; Saurabh, K.; Kumar, A.; Rani, R. Recent developments on solid-state fermentation for production of microbial secondary metabolites: Challenges and solutions. Bioresour. Technol. 2021, 323, 1245-66, https://doi.org/10.1016/j.biortech.2020.124566.

145.John, J. Amylases- Bioprocess and Potential Applications : A Review. Int. J. Bioinfomatica Biol. Sci. 2019, 5, 41-50, https://doi.org/10.5958/2321-7111.2017.00006.3.

146. Banerjee, S.; Maiti, T. K.; Roy, R. N. Production, purification, and characterization of cellulase from Acinetobacter junii GAC 16 . 2, a novel cellulolytic gut isolate of Gryllotalpa africana , and its effects on cotton fiber and sawdust. Ann. Microbiol. 2020, 70, 1-16, https://doi.org/10.1186/s13213-020-01569-6.

147. Sreedharan, S.; Sreedevi, S.; Prakasan, P. Production and Partial Purification of Cellulase from a New Isolate, Penicillium verruculosum BS3. Br. Microibology Res. J. 2015, 9, 1-12, https://doi.org/10.9734/BMRJ/2015/17865.

148.Sigh, N. P.; Dayal, A.; Sharan, A. K. Production of cellulase enzyme by Aspergillus niger, Aspergillus terreus and Pencillium sp. isolated from soil. Ann. Plant Sci., 2020, 9, 3991-3998, http://dx.doi.org/10.5281/aps.2020.9.9.1.

149. Islam, F.; Roy, N. Screening, purification and characterization of cellulase from cellulase producing bacteria 
in molasses. BMC Res. Notes, 2018, 11, 1-6. https://doi.org/10.1186/s13104-018-3558-4.

150. Shahriarinour, M.; Ramanan, R. N. Purification and Characterisation of Extracellular Cellulase Main Components from Aspergillus terreus. Bioresour. Technol. 2015, 10, 4886-4902, http://dx.doi.org/10.15376/biores.10.3.4886-4902.

151. Brammacharry, U. Production and characterization of protease enzyme from Bacillus laterosporus. African J. Microbiol. Res. 2018, 4, 1057-1063, https://doi.org/10.5897/AJMR.9000592.

152.Pant, G. V. N. S.; Gaurav, P.; Anil, P.; Bera, J. V. P.; Sayantan, D.; Kumar, A.; Panchpuri, M.; Gyana, R. Production, optimization and partial purification of protease from Bacillus subtilis. Integr. Med. Res. 2015, 9, 50-55, https://doi.org/10.1016/j.jtusci.2014.04.010.

153. Ishaku, K.; Inuwa, M.; Moses, O. Purification, characterization and optimization conditions of protease produced by Aspergillus brasiliensis strain BCW2. Sci. African 2020, 8, e003-98, https://doi.org/10.1016/j.sciaf.2020.e00398.

154. Gimenes, N.; Silveira, E.; Tambourgi, E. An Overview of Proteases: Production, Downstream Processes and Industrial Applications. Separation and Purification Reviews 2021, 50, 223-243, https://doi.org/10.1080/15422119.2019.1677249.

155. Ahmed, M. E. Extraction and purification of protease from Aspergillus niger isolation. Pharm. Pharmacol. Int. J. 2018, 6, 96-99, https://doi.org/10.15406/ppij.2018.06.00162.

156.Lakshmi, B. K. M.; Muni Kumar, D.; Hemalatha, K. P. J. Purification and characterization of alkaline protease with novel properties from Bacillus cereus strain S8. Journal of Genetic Engineering and Biotechnology 2018, 16, 295-304, https://doi.org/10.1016/j.jgeb.2018.05.009.

157. Manan M. A.; Webb, C. Design aspects of solid state fermentation as applied to microbial bioprocessing. $J$. Appl. Biotechnol. Bioeng. 2017, 4, 511-532, https://doi.org/10.15406/jabb.2017.04.00094.

158. Fasim, A.; More, V. S.; More, S. S. Large-scale production of enzymes for biotechnology uses. Curr. Opin. Biotechnol. 2021, 69, 68-76, https://doi.org/10.1016/j.copbio.2020.12.002.

159. Herna'ndez, A. L.; Martı'nez, J. R. Solid state fermentation ( SSF ): diversity of applications to valorize waste and biomass. Biotechnology 2017, 7, 1-9, https://doi.org/10.1007/s13205-017-0692-y.

160. Mukherjee, S. Isolation and Purification of Industrial Enzymes: Advancement in enzyme technology. In Advances in Enzyme Technology, $1^{\text {st }}$ edition, Ram Sarup Singh, Reeta Rani Singhania, Christian Larroche, Elsevier B.V, Amsterdam, Netherlands 2019, 41-70, https://doi.org/10.1016/B978-0-444-64114-4.00002-9.

161.Patel, S.; Naveen, R.; Dhananjai, S.; Shivam, S. Lipases : Sources, Production, Purification, and Applications, Recent Pat. Biotechnol. 2019, 12, 1-12, https://doi.org/10.2174/1872208312666181029093333.

162.Toke, E. R.; Nagy, V.; Recseg, K.; Szakács, G.; Poppe, L. Production and application of novel sterol esterases from aspergillus strains by solid state fermentation. JAOCS Journal of the American Oil Chemists' Society 2007, 84, 907-915, https://doi.org/10.1007/s11746-007-1127-4.

163.Torres, G. R.; Sebastián, B.; Mario, D. P.; Ashok, C. Production and Purification of a Solvent-Resistant Esterase from Bacillus licheniformis S-86. Appl. Biochem. Biotechnol. 2018, 151, 221-232, https://doi.org/10.1007/s12010-008-8181-8.

164. Chen, Z.; Cheng-cheng, C.; Zhe, L.; Guang-lei, J.; Hong, H.; Chi, Z. Production, purification, characterization and gene cloning of an esterase produced by Aureobasidium. In Process Biochemistry, $1^{\text {st }}$ edition, J-J. Zhong E.J. Vandamme Boudrant, J, Elsevier Ltd, Singapore 2018, 1-41, https://doi.org/10.1016/j.procbio.2016.12.006.

165.Bhardwaj, A.; Kamal, K. D.; Kapoor, A.; Smita, M.; Gupta, R. Purification and Properties of an Esterase from Bacillus licheniformis and it's Application in Synthesis of Octyl Acetate. Open Microbiol. J. 2020, 15, 113-121, https://doi.org/10.2174/1874285802014010113.

166. Ahmad, T.; Singh, R. S.; Gupta, G.; Sharma, A.; Kaur, B. Metagenomics in the search for industrial enzymes, Biomass, Biofuels, Biochemicals. In Advances in Enzyme Technology, ${ }^{\text {st }}$ edition, Ram Sarup Singh, Reeta Rani Singhania, Christian Larroche, Elsevier B.V, India 2019, 419-451, https://doi.org/10.1016/B978-0-44464114-4.00015-7.

167. Madhavan, A .; Sindhu, R.; Parameswaran, B.; Sukumaran, R. K.; Pandey, A. Metagenome Analysis: a Powerful Tool for Enzyme Bioprospecting. Appl. Biochem. Biotechnol., 2017, 183, 636-651, https://doi.org/10.1007/s12010-017-2568-3.

168. Visvanathan, R.; Jayathilake, C.; Liyanage, R.; Sivakanesan, R. Applicability and reliability of the glucose oxidase method in assessing $\alpha$-amylase activity. Food Chem. 2019, 275, 265-272, https://doi.org/10.1016/j.foodchem.2018.09.114. 
169.Kwon, K. K.; Yeom, S. J.; Lee, D. H.; Jeong, K. J.; Lee, S. G. Development of a novel cellulase biosensor that detects crystalline cellulose hydrolysis using a transcriptional regulator. Biochem. Biophys. Res. Commun. 2018, 495, 1328-1334, https://doi.org/10.1016/j.bbrc.2017.11.157.

170. Oliveira-Silva, R.; Sousa-Jerónimo, M.; Botequim, D.; Silva, N. J. O.; Paulo, P. M. R.; Prazeres, D. M. F. Monitoring Proteolytic Activity in Real Time: A New World of Opportunities for Biosensors. Trends Biochem. Sci. 2020, 45, 604-618, https://doi.org/10.1016/j.tibs.2020.03.011.

171.Shi, F. H. J.; Zhang, S.; Zheng, M.; Deng, Q.; Zheng, C.; Li, J. A novel fluorometric turn-on assay for lipase activity based on an aggregation-induced emission (AIE) luminogen. Sensors Actuators B Chem. 2017, 238, 765-771, https://doi.org/10.1016/j.snb.2016.07.116.

172.Xiaolong, C. C.; Gaihua, Z.; Jiajin, D.; Yuanyi, L.; Xiaogang, Y.; Mei, H.; Danqun, H. C. An ultrasensitive and point-of-care strategy for enzymes activity detection based on enzyme extends activators to unlock the ssDNase activity of CRISPR/Cas12a (EdU-CRISPR/Cas12a). Sensors Actuators B Chem. 2021, 333, 129553, https://doi.org/10.1016/j.snb.2021.129553.

173.Pan, R.; Jiang, D. Nanokits for the electrochemical quantification of enzyme activity in single living cells, In Methods in Enzymology, 1st ed., Nancy L. Allbritton, Michelle L. Kovarik, Elsevier Inc., Jiangsu, China 2019, 628, 173-189, https://doi.org/10.1016/bs.mie.2019.06.015.

174.Gang, M. L.; Raymond, E. Chemical probes for spatially resolved measurement of active enzymes in single cells. In Methods in Enzymology, 1st ed., Nancy L. Allbritton, Michelle L. Kovarik, Elsevier Inc., United States 2019, 628, 243-262, https://doi.org/10.1016/bs.mie.2019.06.017.

175.Huang, H. Matrix metalloproteinase-9 (MMP-9) as a cancer biomarker and MMP-9 biosensors: Recent advances. Sensors (Switzerland) 2018, 18, 5-7, https://doi.org/10.3390/s18103249. 